
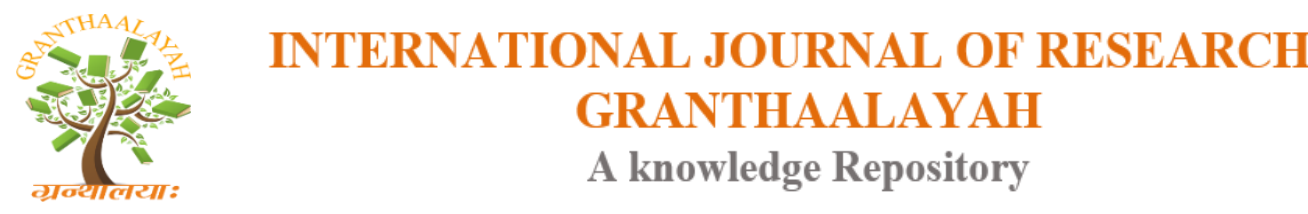

Science

\title{
RECENT DEVELOPMENT OF BIODEGRADATION TECHNIQUES OF POLYMER
}

\author{
Aadrsh Kumar Tiwari *1, Manisha Gautam 1, Hardesh K Maurya *1 \\ ${ }^{* 1}$ Department of Applied Chemistry, Babasaheb Bhimrao Ambedkar University, Lucknow- \\ 226025, India
}

\begin{abstract}
Lack of degradability and the closing of landfill sites as well as growing water and land pollution problems have led to concern about plastics. With the too much use of plastics and increasing pressure being placed on capacity available for plastic waste disposal, the need for biodegradable plastics and biodegradation of plastic wastes has assumed increasing importance in the last few years. Awareness of the waste problem and its impact on the environment has awakened new interest in the area of degradable polymers. The interest in environmental issues is growing and there are increasing demands to develop material which do not burden the environment significantly. This project reviews the biodegradation of biodegradable and also the conventional synthetic plastics, types of biodegradations of biodegradable polymers also use of a variety of "Recent development of biodegradation techniques" for the analysis of degradation in vitro.
\end{abstract}

Keywords: Biodegradation; Biodegradation Polymers; Biofragmentation; Recycling; Oligomeric; Vitro; Conentional; Homogenicity.

Cite This Article: Aadrsh Kumar Tiwari, Manisha Gautam, and Hardesh K Maurya. (2018). "RECENT DEVELOPMENT OF BIODEGRADATION TECHNIQUES OF POLYMER." International Journal of Research - Granthaalayah, 6(6), 414-452. https://doi.org/10.29121/granthaalayah.v6.i6.2018.1389.

\section{Introduction}

Approximately 140 million tones of synthetic polymers are produced world-wide every year. Since polymers are very stable, their degradation cycles in the biosphere are limited. Environmental pollution by synthetic polymers, such as waste plastics and water-soluble synthetic polymers in wastewater has been recognized as a main problem. In view of this, energetic, chemical and biological polymer-degrading techniques have been studied broadly during the last three decades [1].

Usage of certain micro-organisms and enzymes to degrade polymers are classified as the biodegradating method of polymers. 
Very small variations in the chemical structures of polymer could lead to large changes in their bio-degradability.

The bio-degradability depends on the molecular weight, molecular from and crystallinity.

It decreases with increase in molecular weight, while monomers, dimers and repeating units degrade easily.

Most bio-degradable polymers belong to thermo-plastics \{e.g. Poly (lactic acid), poly (hydroxylalkanoate), poly (vinyl alcohol)\} or plants polymers (e.g. Cellulose and starch). Thermo-plastics from poly-olefins are not bio-degradable, even if some of them have pro-oxidant additives making them photo and thermo-degradable, the assimilation of oligomers or monomers by micro-organism is not so far totally proved.

In recent years, innovating experiments are realized to combine both approaches, the results are the production of polymeric materials with controlled life spans.

The considered materials must be resistant during their use and must have bio-degradable properties at the end of their useful life.

Today, a fast-growing industrial competition is established for the production of a great variety of controlled life span materials. It is important to develop new comparative tests to estimate their bio-degradability. Actually, it seems to have confusion in the interpretation of bio-degradation, bio-fragmentation and bio-deterioration. Here after, we are giving attention to the meaning of polymer bio-degradation.

Earlier, bio-degradation was defined as a decomposition of substances by the action of microorganisms. This action leads to the recycle of carbon, the mineralization ( $\mathrm{CO}_{2}, \mathrm{~h}_{2} \mathrm{O}$ and salts) of organic compounds and the generation of new biomass. At present, the complexity of biodegradation is better understood and cannot be easily summarized [2].

The bio-degradation of polymeric materials includes several steps:

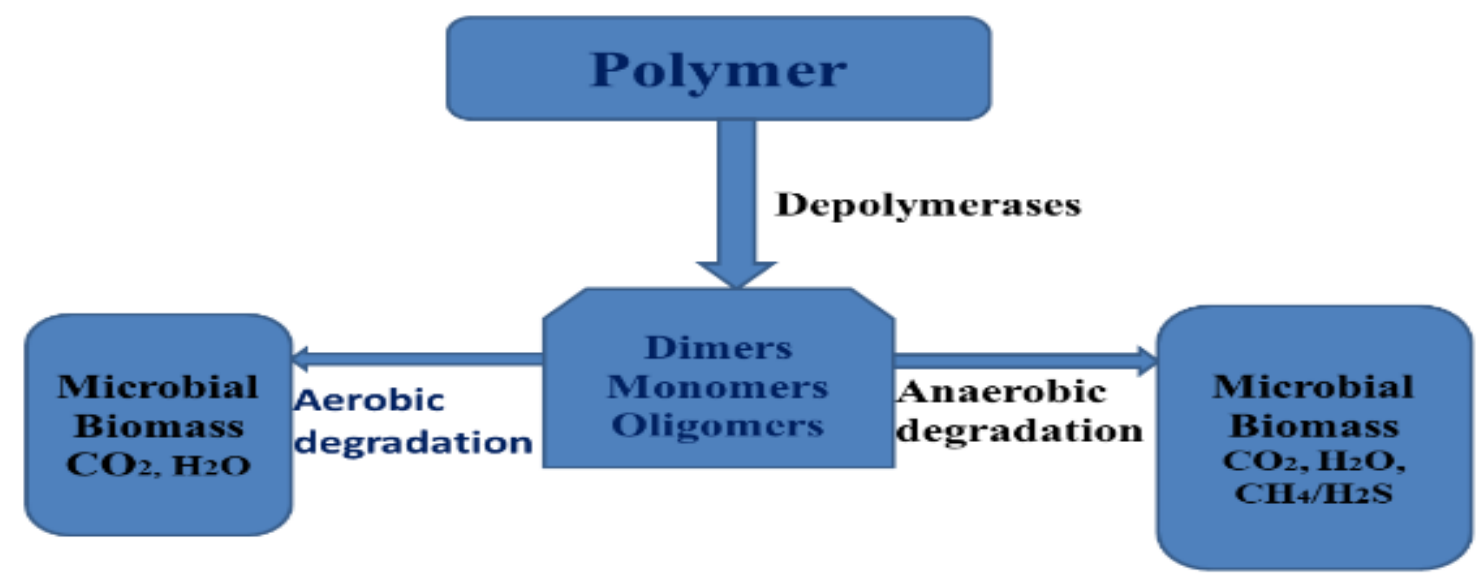

Figure 1: Reaction pathways during biodegradation 


\section{General Degradation Processes}

Polymeric materials can be potential source of carbon and energy for heterotrophic microorganisms (including bacteria and fungi) in several ways. Degradability of polymeric materials is highly variable from easily degradable to resistant to degradation. Since plasticizers and chemical fillers are commonly added in the polymer formulations and manufacturing processes, these chemicals may serve as good nutrients for the immediate surrounding microorganisms developed on polymer surfaces.

After initiation of degradation of either the polymer matrices or the additives, environmental conditions play a critical role determining the dominant groups of microorganisms and the biochemical degradative pathways. Under aerobic conditions when $\mathrm{O}_{2}$ is effortlessly available, aerobic heterotrophic microorganisms are mostly liable for degradation of complex materials, with microbial biomass, $\mathrm{CO}_{2}$, and $\mathrm{H}_{2} \mathrm{O}$ as the final products. In contrast, under strictly anaerobic conditions in the absence of $\mathrm{O}_{2}$, anaerobic microorganisms are responsible for polymer degradation, and the products are microbial biomass, $\mathrm{CO}_{2}, \mathrm{CH}_{4}$ and $\mathrm{H}_{2} \mathrm{O}$ under methanogenic conditions or $\mathrm{H}_{2} \mathrm{~S}, \mathrm{CO}_{2}$ and $\mathrm{H}_{2} \mathrm{O}$ under sulfidegenic conditions. Both environmental conditions are commonly found in natural environments, but aerobic conditions are capable of sustaining a greater population of microorganisms than anaerobic ones.

\section{Degradation}

Polymer degradation (Scheme 1) is a change in the properties-tensile strength, color, shape, etc. of a polymer or polymer-based product under the control of one or more environmental factors such as heat, light or chemicals (such as acids, alkalis and some salts). These changes are usually undesirable, such as cracking and chemical breakdown of products or, more rarely, desirable, as in biodegradation, or deliberately lowering the molecular weight of a polymer for recycling. The changes in properties are often termed "aging". Degradation can be useful for recycling/reusing the polymer waste to prevent or reduce environmental pollution.

Polymeric molecules are very large (on the molecular scale), and their unique and useful properties are mainly a result of their size any loss in chain length lowers tensile strength and is a primary cause of premature cracking [2].

Today there are primarily seven valuable polymers that use in high volume: Polyethylene (PE), Polypropylene (PP), Polyvinyl-chloride (PVC), Polyethylene tere-phthalate (PET), Polystyrene (PS), Polycarbonate (PC) and Poly(methylmethacrylate) (PMMA). These make up nearly $98 \%$ of all polymers and plastics encountered in daily life. Each of these polymers has its own quality modes of degradation and resistances to heat, light and chemicals.

- Polyethylene, polypropylene, and poly (methyl methacrylate) are sensitive to oxidation and UV radiation, while PVC may discolor at high temperatures due to loss of hydrogen chloride gas, and become very brittle.

- PET is sensitive to hydrolysis and attack by strong acids, while polycarbonate depolymerizes rapidly when exposed to strong alkalis.

- For example, polyethylene usually degrades by random scission - that is by a random breakage of the linkages (bonds) that hold the atoms of the polymer together. When this 
polymer is heated above $450{ }^{\circ} \mathrm{C}$ it becomes a complex mixture of molecules of various sizes that resemble gasoline. Other polymers-like poly- $\alpha$-methyl styrene undergo 'specific' chain scission with breakage taking place only at the ends; they literally unzip or de-polymerize to become the constituent monomers.

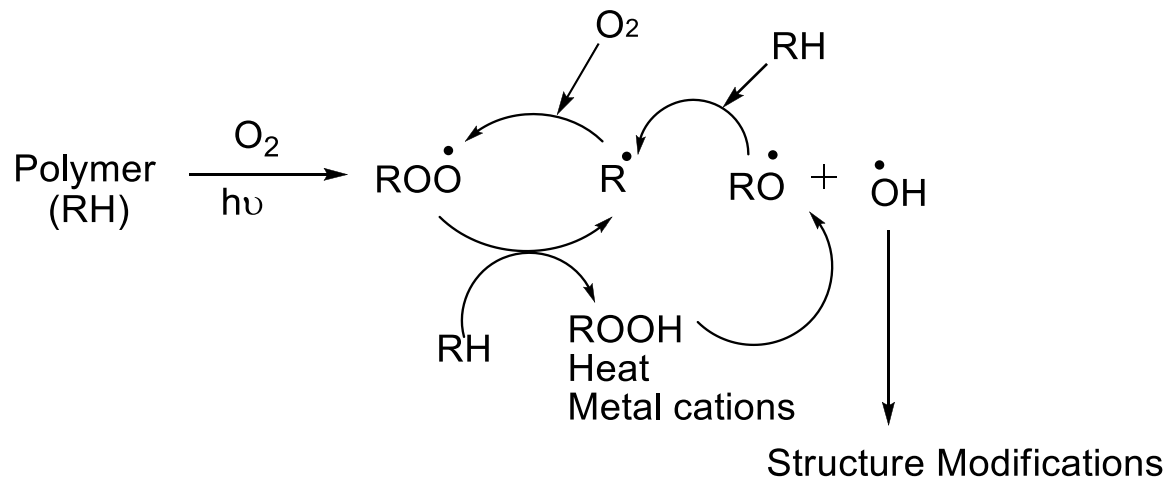

Scheme 1: Polymer degradation

\section{Types of Polymer Degradation}

There are definite types of degradations which are usually referred to as polymer change as well. Further you get to know about the most common types of degradations of polymers. It is also to be noted that degradation types are numerous but only a few are explained here to explain the initiative in full [3].

1) Photo-induced degradation

2) Thermal degradation

3) Chemical degradation

4) Mechanical degradation

5) Biodegradation

\subsection{Photo-Induced Degradation}

Most polymers can be degraded by photolysis to give lower molecular weight molecules. Electromagnetic waves with the energy of visible light or higher, such as ultraviolet light-ray and gamma rays are usually involved in such reactions. This mainly happens when high-intensity rays such as X-rays, gamma rays, and even Ultraviolet rays react with the polymers. UV stabilization is a fact which is added to polymers while they are developed. However, in most of the cases, time is another factor which causes this issue. UV stabilization fades during the course of time so it is advent that this type of issue occurs for sure. The carbon bonds within the polymers are broken and this leads to issues which lead to the brittle polymer as a result. Photo-induced degradation shown in scheme 2 . 


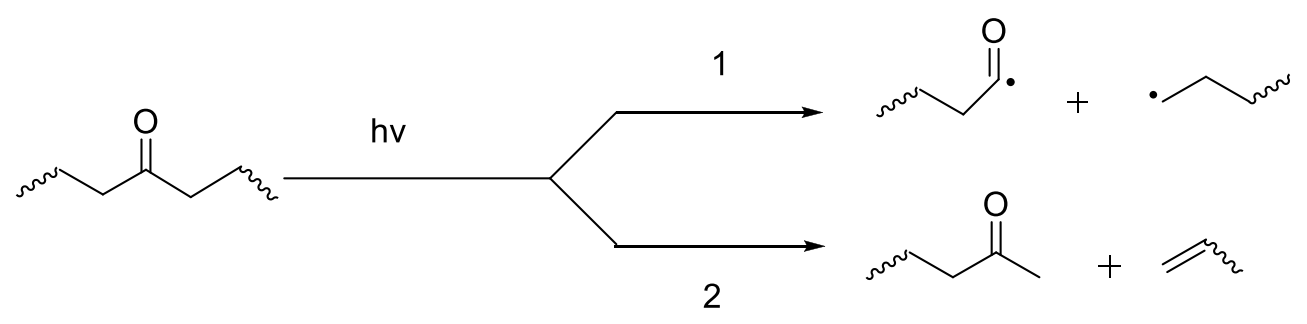

Scheme 2: Photo-induced degradation

\subsection{Thermal Degradation}

It is exposure to the high temperature which causes degradation. It makes the developers realize that the tensile strength of polymers is to be increased. However, it is not possible as at times the thermal point increases and the polymer covalent bonds are severely affected. There is a hydrogen atom which is embedded in each polymer chain. This atom makes sure that the bonds are kept together completely and in a commanding manner. When thermal degradation takes place the hydrogen atom in question completely evaporates from within the structure. The polymer bonds are broken which leads to issues in a long run.

The process of polymerization is also reversed which leads to polymer breaking and eventual loss. Chain-growth polymers like poly (methyl methacrylate) can be degraded by hemolysis at high temperatures to give monomers, oils, gases and water [3]. Thermal degradation mechanism shown in Figure 2.

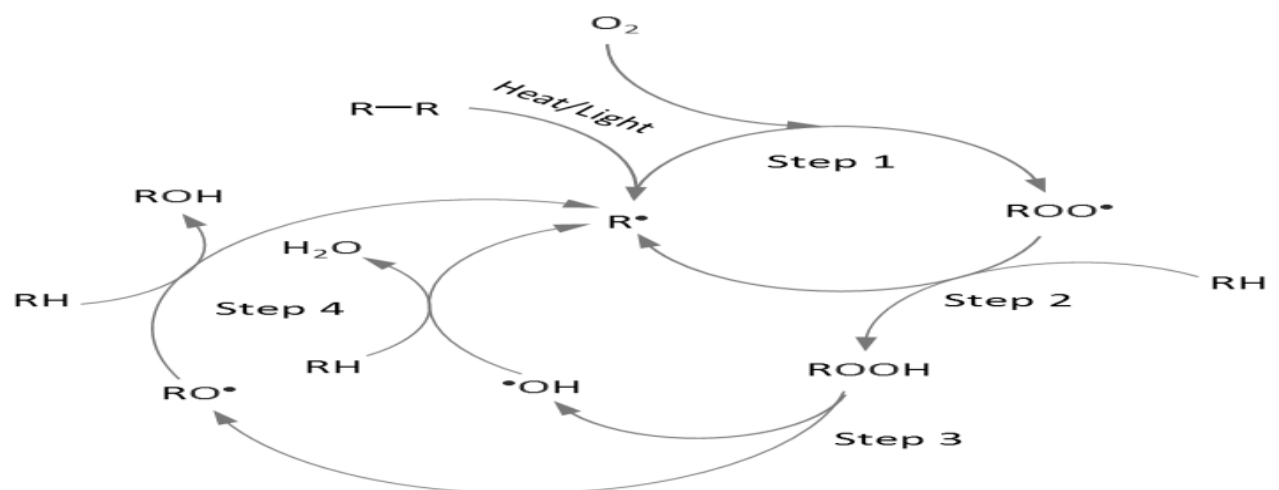

Figure 2: Thermal degradation mechanism

The example of PVC eliminates $\mathrm{HCl}$, under $100-200{ }^{\circ} \mathrm{C}$ has been shown in Scheme 3.

stage 1

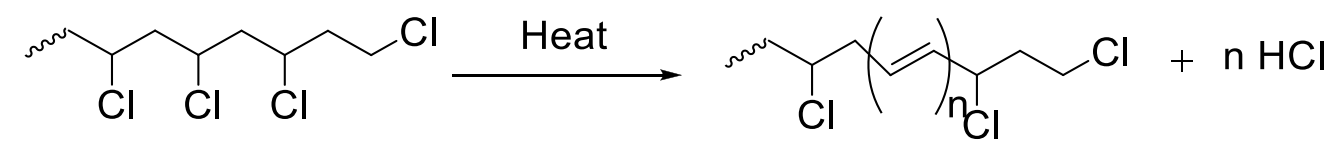

stage 2
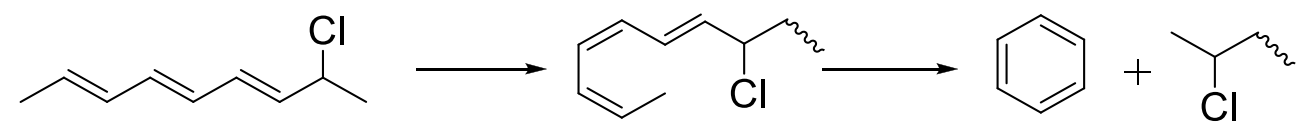

Scheme 3: Thermal degradation of PVC 


\subsection{Chemical Degradation}

This is a complex process with same end result i.e. change in chemical properties of the polymer. It also makes sure that the bonds are broken in such a manner that generally structure of the polymer is altered completely. The main there aspects of chemical degradation of polymers which are as under:

- Degradation of polymer by Ozone which mainly targets rubber based polymers.

- PVC degradation which is mainly done by chlorine. Joints of polymer piping are affected.

- Degradation of polyester, High-temperature polymers are also degraded by the same effect.

High-temperature polyurethane is also degraded by same degradation methods which are regarded as the most destructive force of all. Types of chemical degradations [3].

1) Hydrolysis

2) Oxidative

3) Decarboxilation

\subsubsection{Hydrolysis Degradation}

Hydrolysis is the cleavage of bonds in functional groups by reaction with water. This reaction occurs mainly in polymers that take up a lot of moisture and that have water-sensitive groups in the polymer backbone. Some synthetic polymers that degrade when exposed to moisture include polyesters, poly-anhydrides, polyamides, poly-ethers, and polycarbonates. The rate of hydrolytic degradation (Fig. 3) can vary from hours to years depending on the type of functional group, backbone structure, morphology and $\mathrm{pH}$. Polymers that easily degrade in the presence of water include poly-anhydrides, aliphatic polyesters with short mid-blocks like poly-lactic acid and certain poly (amino acids) like poly (glutamic acid). Assuming similar mid-blocks, the rate of hydrolysis decreases in the order anhydride > ester $>$ > amide $>>$ ether.

The hydrolysis of semi-crystalline polymers such esters, amides and anhydrides occurs usually in two stages; during the first stage, the degradation occurs by diffusion of water into the amorphous regions with succeeding hydrolysis. The second stage starts when moisture penetrates and degrades the crystalline regions. Thus, a bimolecular weight distribution is observed at any time during these two stages. The erosion rate usually increases over time due to decreased crystallinity and molecular weight as well as increased water solubility which turns the polymer into a beehiveor sponge-like porous body with only minor dimensional changes. Surface corrosion, on the other hand, occurs at a constant erosion rate and does not affect the molecular weight but produces dimensional changes [4]. 


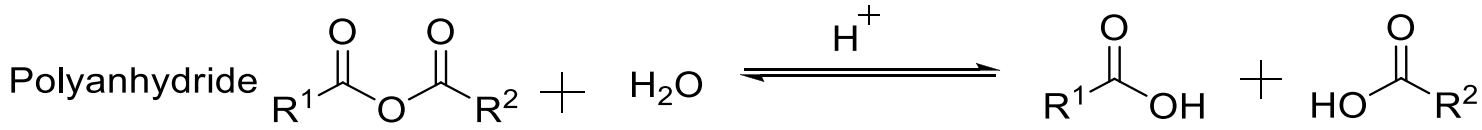

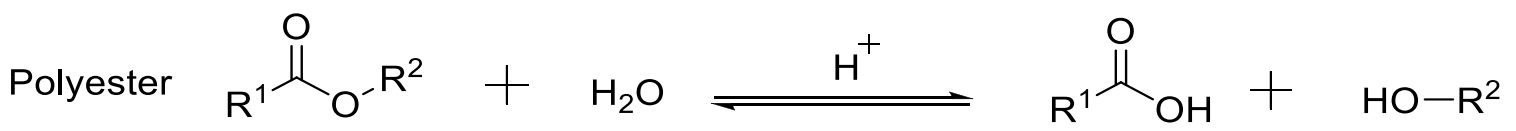

Polyamide<smiles>[R]NC([R])=O</smiles><smiles>[CH+]=C</smiles><smiles>[R]C(=O)O</smiles><smiles>[R]N</smiles>

Polyether<smiles>[R]O[R]</smiles><smiles>O</smiles><smiles>[CH+]C</smiles>

Figure 3: Hydrolysis degradation of polymers

\subsubsection{Oxidative Degradation}

In an atmosphere containing oxygen, polymers are oxidized, incompletely degraded and crosslinked. Various low molecular weight products are evolved and groups containing oxygen (hydroxyl, peroxide, carbonyl, aldehyde, etc.) are formed along the polymer chain or at its ends. The exposure of a polymer to oxygen is characterized by an induction period during which the polymer does not show any observable changes and there is no evidence of oxygen absorption. This period is nevertheless important in the process of polymer oxidation because small amounts of hydro peroxides are formed and they initiate the subsequent rapid auto-oxidation of the polymer. An increase in temperature reduces the induction period and accelerates the auto-oxidation.

In some cases, when the polymer contains trace amounts of peroxide impurities or catalysts such as metallic salts, the induction period is not observed at all and the process of catalytic oxidation begins immediately. The decomposition of the hydro-peroxides is commonly recognized as the process responsible for further rapid oxidation [5].

- The investigation of polymer oxidation is carried out with:

1) Solid polymers (chiefly in the form of films)

- at the temperature at which the polymer is used (chiefly room temperature);

- at high temperatures (thermal oxidation), either below the temperature of polymer softening (long-term ageing) or above the temperature of polymer softening.

2) Solutions of polymers, either at room temperature or at the boiling point of the solvent or in its vicinity.

The oxidation of polymers is also examined on exposure to:

1) Visible and UV light (photo-oxidation),

2) Nuclear radiation (oxidizing radiation),

3) Electrical discharge,

4) Ultrasonic energy,

Comminuting and plastic or mechanical treatments. 
The agents predominantly effecting the oxidation of polymers are:

1) Molecular oxygen

2) Singlet oxygen

3) Atomic oxygen

4) Ozone

As a rule an increase in temperature reduces the induction period and accelerates the autooxidation.

Examples: In presence of Ozone

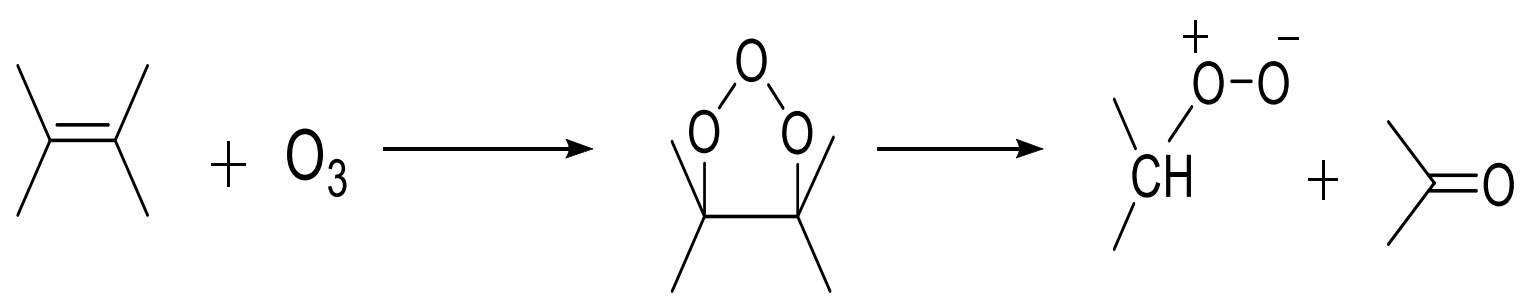

Scheme 4: oxidation in presence of ozone

In presence of Oxygen

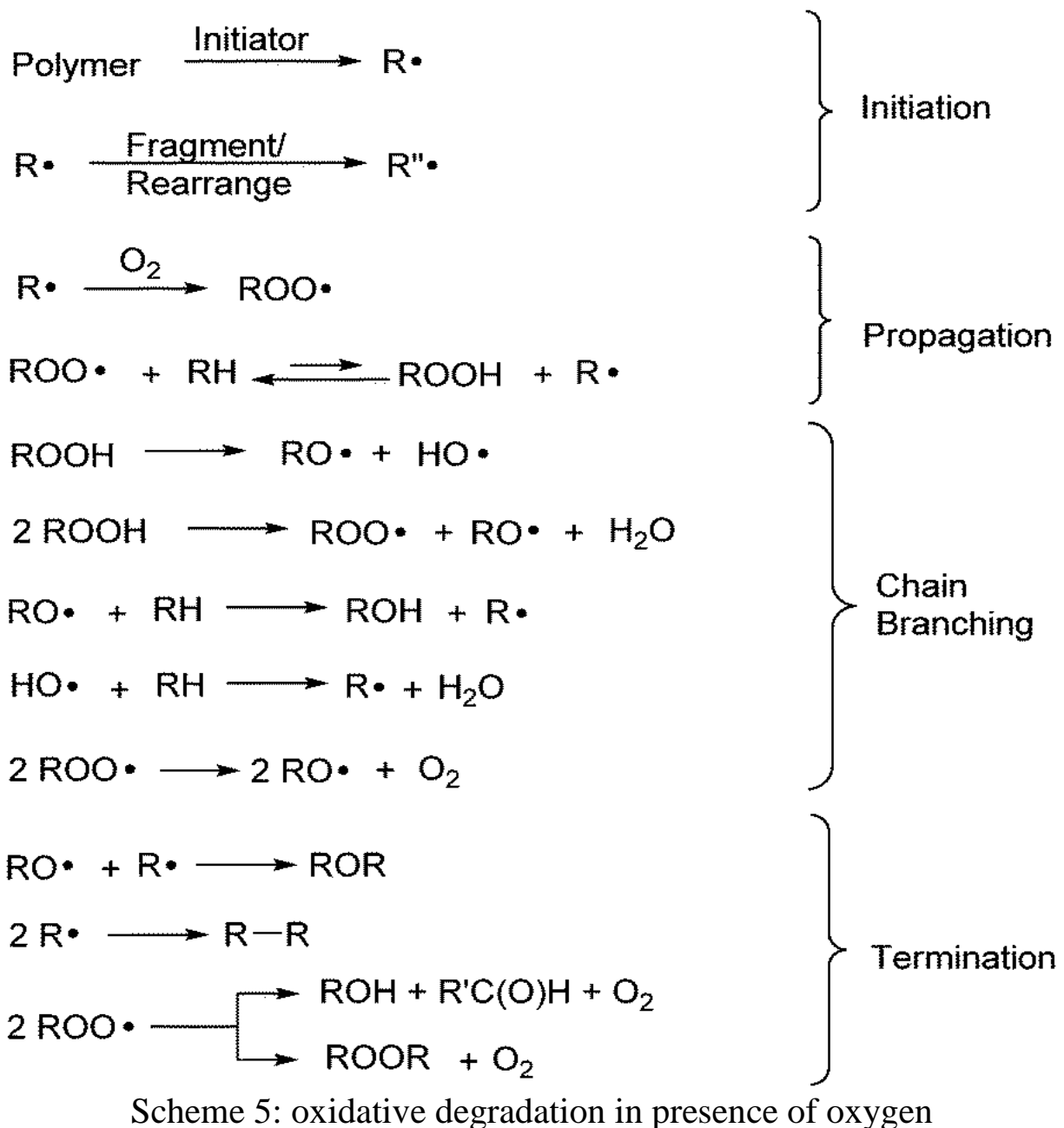




\subsubsection{Decarboxilation Degradation}

Decarboxylation is a chemical reaction that removes a carboxyl group and releases carbon dioxide $\left(\mathrm{CO}_{2}\right)$. Usually, decarboxylation refers to a reaction of carboxylic acids, removing a carbon atom from a carbon chain [6].

In presence of heat<smiles>CCCCCc1ccc([C@@H]2C=C(C)CC[C@H]2C)c(O)c1C(=O)O</smiles>

tetrahydrocannabinol<smiles>CCCCCc1cc(O)c2c(c1)OC(C)(C)[C@@H]1CCC(C)=C[C@H]21</smiles>

tetrahydrocannabinolic acid

Scheme 6: Decarboxylation degradation in presence of heat

In presence of free radical<smiles>[R]OC(=O)C(C)CC(CC)C(=O)O[R]</smiles>

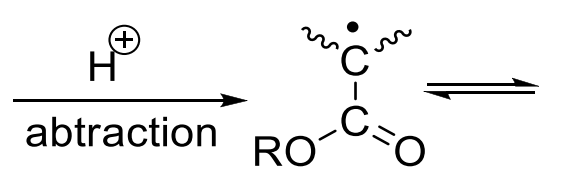<smiles>[R]OC(O)=C(C)C</smiles>

Scheme 7: Decarboxilation degradation in presence of free radical

\subsection{Mechanical Degradation}

The polymer chain is ruptured by mechanical means. The effect is to reduce the polymer molecular mass. This is sometimes done purposely. When polymers, or solutions of polymers, are subjected to large shear forces chain scission occurs. The experimental evidence published to date, and recently reviewed by Scanlan and Watson 1, shows quite obviously that the bonds near the ends of the polymer chain are much less probable to be broken during mechanical degradation than are the bonds closer the centre of the chain to break at centre [7].

Example: Mastication of natural rubber but if it occurs in service the polymer properties will be adversely affected. Usually the chain break is made permanent by oxygen attack and mechanical degradation. Is more accurately described as mechanochemical degradation.

\subsection{Biodegradation}

There is a world-wide research effort to develop biodegradable polymers as a waste management option for polymers in the environment. Biodegradation (i.e. biotic degradation) is a chemical degradation of materials (i.e. polymers) provoked by the action of microorganisms such as 
bacteria, fungi and algae. The most common definition of a biodegradable polymer is "a degradable polymer where in the primary degradation mechanism is from side to side the action of metabolism by micro-organisms." Biodegradation is considered a type of degradation involving biological activity. Biodegradation is expected to be the major mechanism of loss for most chemicals released into the environment. This process refers to the degradation and assimilation of polymers by living microorganisms to produce degradation products. The most important organisms in biodegradation are fungi, bacteria and algae. Natural polymers (i.e., proteins, polysaccharides, nucleic acids) are degraded in biological systems by oxidation and hydrolysis. Biodegradable materials degrade into biomass, carbon dioxide and methane. In the case of synthetic polymers, microbial utilization of its carbon backbone as a carbon source is required.

Bacteria important in the biodegradation process include, inter alia, Bacillus (capable of producing thick-walled endospores that are resistant to heat, radiation and chemical disinfection), Pseudomonas, Klebsiella, Actinomycetes, Nocardia, Streptomyces, Thermoactinomycetes, Micromonospora, Mycobacterium, Rhodococcus, Flavobacterium, Comamonas, Escherichia, Azotobacter and Alcaligenes (some of them can accumulate polymer up to $90 \%$ of their dry mass). Temperature is one of the most important factors affecting microorganism growth. Also important are sources of carbon and nitrogen, and $\mathrm{pH}$. Fungi active in the biodegradation process are Sporotrichum, Talaromyces, Phanerochaete, Ganoderma,Thermoascus, Thielavia, Paecilomyces, Thermomyces, Geotrichum, Cladosporium, Phlebia, Trametes, Candida, Penicillium, Chaetomium, and Aerobasidium. The biodegradation process can be divided into (1) aerobic and (2) anaerobic degradation (Fig.4).

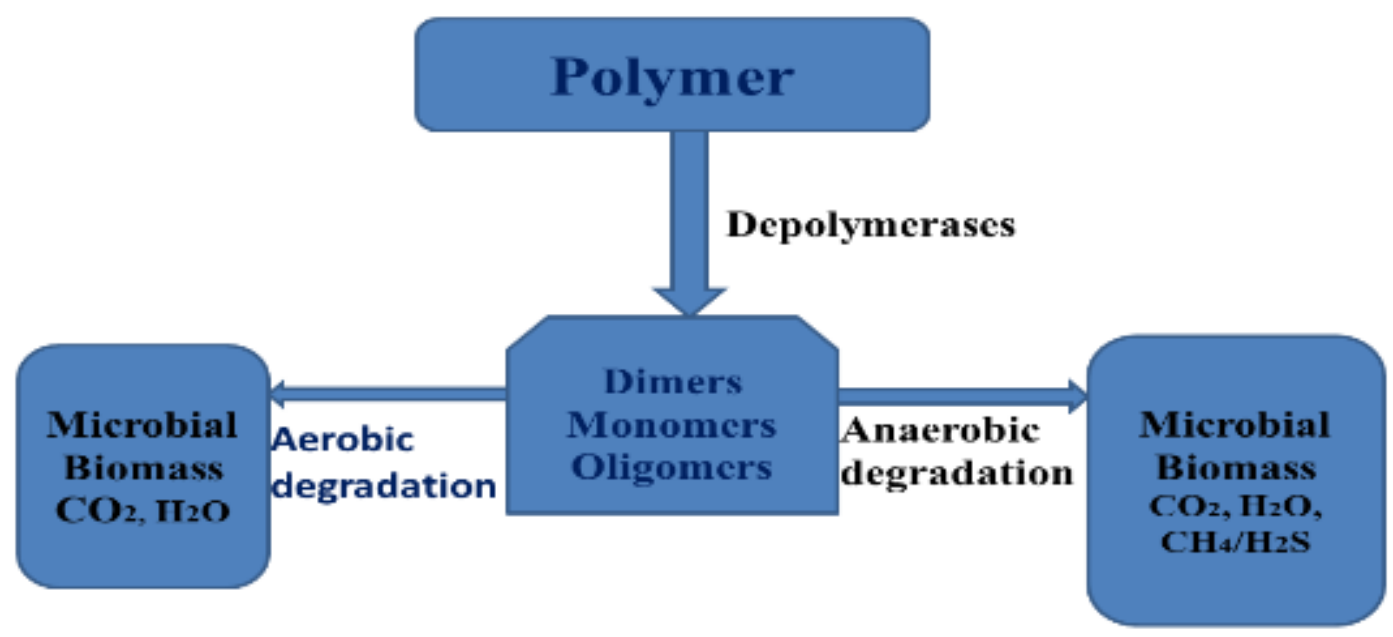

Figure 4: Scheme of polymer degradation under aerobic and anaerobic conditions

If oxygen is present, aerobic biodegradation occurs and carbon dioxide is produced. If there is no oxygen, an anaerobic degradation occurs and methane is produced instead of carbon dioxide. When conversion of biodegradable materials or biomass to gases (like carbon dioxide, methane, and nitrogen compounds), water, salts, minerals and residual biomass occurs, this process is called mineralization. Mineralization is complete when all the biodegradable materials or biomass are consumed and all the carbon is converted to carbon dioxide. Biodegradable materials have the proven capability to decompose in the most common environment where the material is disposed, within one year, through natural biological processes into non-toxic carbonaceous soil, water or 
carbon dioxide. The chemical structure (responsible for functional group stability, reactivity, hydro-phylicity and swelling behavior) is the most important factor affecting the biodegradability of polymeric materials. Other important factors are inter alia, physical and physico-mechanical properties, e.g., molecular weight, porosity, elasticity and morphology (crystalline, amorphous) [8].

\section{Biodegradable Polymers}

Biodegradable polymers are a specific type of polymer that breaks down after its intended purpose to result in natural byproducts such as gases $\left(\mathrm{CO}_{2}, \mathrm{~N}_{2}\right)$, water, biomass, and inorganic salts. These polymers are found both naturally and synthetically made, and largely consist of ester, amide, and ether functional groups. Their properties and breakdown mechanism are determined by their exact structure. These polymers are often synthesized by condensation reactions, ring opening polymerization, and metal catalysts. There are vast examples and applications of biodegradable polymers. Bio-based packaging materials have been introduced as a green alternative in the past decades, among which, edible films have gained more attention due to their environmentallyfriendly characteristics, huge variety and avail-ability, non-toxicity, and low-cost [9].

\subsection{Structure}

Biodegradable polymers tend to consist of ester, amide, or ether bonds. In general, biodegradable polymers can be grouped into two large groups based on their structure and synthesis. One of these groups is agro-polymers, or those derived from biomass. The other consists of bio-polyesters, which are those derived from microorganisms or synthetically made from either naturally or synthetic monomers. Agro-polymers include polysaccharides, like starches found in potatoes or wood, and proteins, such as animal based whey or plant derived gluten. Poly-saccharides consist of glycolsidic bonds, which take a hemiacetal of a saccharide and binds it to a alcohol via loss of water. Proteins are made from amino acids, which contain various functional groups. These amino acids come together again through condensation reactions to form peptide bonds, which consist of amide functional groups. Examples of bio-polyesters includes poly-hydroxy-butyrate and polylactic acid.

\subsection{Properties}

Even though biodegradable polymers have numerous applications, there are properties that tend to be common among them. All biodegradable polymers should be stable and durable enough for use in their exacting application, but upon disposal they should easily break down. Polymers, specifically biodegradable polymers, have extremely strong carbon backbones that are difficult to break, such that degradation often starts from the end-groups. Since the degradation begins at the end, a high surface area is common as it allows easy access for either the chemical, light, or organism. Biodegradable polymers also tend to have minimal chain branching as this cross linking often decreases the number of end groups per unit weight. Crystallinity is often low as it also inhibits access to end groups. A low degree of polymerization is normally seen, as hinted at above, as doing so allows for more accessible end groups for reaction with the degradation initiator. Another commonality of these polymers is their hydro-phillicity. Hydrophobic polymers and end 
groups will prevent an enzyme from easily interacting if the water-soluble enzyme cannot easily get in contact with the polymer.

Other properties of biodegradable polymers that are common among those used for medicinal usages include

1) Non-toxic,

2) Capable of maintaining good mechanical integrity until degraded, and

3) Capable of controlled rates of degradation.

A goal is not to elicit the immune response, and the products of degradation also need not to be toxic. These are important as biodegradable polymers are used for drug delivery where it is critical to slowly release the drug into the body over time instead of all at once and that the pill is stable in the bottle until ready to be taken. Factors controlling the rate of degradation include:

1) Percent crystallinity

2) Molecular weight

3) Hydrophobicity

The degradation rate depends on the location in the body, which influences the environment surrounding the polymer such as $\mathrm{pH}$, enzymes concentration, and amount of water among others. These are quickly decomposed.

\subsection{Synthesis}

One of the most important and most studied groups of biodegradable polymers are polyesters. Polyesters can be synthesized in a number of ways including direct condensation of alcohols and acids, ring opening polymerizations (ROP), and metal-catalyzed polymerization reactions. A great disadvantage of the step-wise polymerization via condensation of an acid and an alcohol is the need to continuously remove water from this system in order to drive the equilibrium of the reaction forward. This can require cruel reaction conditions and long reaction times, resulting in a wide dispersity. A wide variety of starting materials can be used to synthesize polyesters, and each monomer type endows the final polymer chain with different characteristics and properties. The ROP of cyclic di-meric glycolic or lactic acid forms $\alpha$-hydroxy acids which then polymerize into poly-( $\alpha$-esters $)$. A variety of organo-metallic initiators can be used to start the polymerization of polyesters, including tin, zinc, and aluminum complexes. The most common is tin (II)Octanoate and has been approved as a food additive by the U.S. FDA, but there are still concerns about using the tin catalysts in the synthesis of biodegradable polymers for biomedical uses. The synthesis of poly $(\beta$-esters) and poly $(\gamma$-esters) can be carried out by similar ROP or condensation methods as with poly( $\gamma$-esters). Development of metal-free process that involve the use of bacterial or enzymatic catalysis in polyester formation is also being explored. These reactions have the benefit of generally being region-selective and stereo specific but suffer from the high cost of bacteria and enzymes, long reaction times, and products of low molecular weight. 
Example of routes to polyester formation using lactic acid

a)<smiles>CC(COC(=O)C(C)O)OC(C)C(=O)O</smiles>

b)<smiles>CC(O)C(=O)OC(I)(I)C(F)(F)F</smiles><smiles>CC(O)C(=O)O</smiles><smiles>CC(C)OC(C)C(=O)O</smiles>

Scheme 8: a) Condensation of lactic acid into dimeric lactide followed by ring-opening polymerization of to form poly (lactic acid); b) Direct condensation of lactic acid, demonstrating the need to continuously remove water from the system in order to drive the reaction forward

While polyesters dominate both the research and industrial focus on synthetic biodegradable polymers, other classes of polymers are also of interest. Poly-anhydrides are an active area of research in drug delivery because they only degrade from the surface and so are able to release the drug they carry at a constant rate. Poly-anhydrides can be made via a variety of methods also used in the synthesis of other polymers, including condensation, dehydro-chlorination, dehydrative coupling, and ROP. Polyurethanes and poly (ester amide) s are used in biomaterials. Polyurethanes were initially used for their biocompatibility, durability, resilience, but are more recently being investigated for their biodegradability. Polyurethanes are characteristically synthesized using a diisocyanate, a diol, and a polymer chain extender. The initial reaction is carried out between the diisocyanate and the diol, with the diisocyanate in excess to ensure that the ends of the new polymer chain are isocyanate groups. This polymer can then be reacted with either a diol or a diamine to form urethane or urethane-urea end groups, likewise. The choice of terminal groups affects the properties of the resulting polymer. Additionally, the use of vegetable oil and biomass in the formation of polyurethanes, as well as the conversion of polyurethanes to polyols, is an active area of research.

Synthesis of biodegradable polymer are shown in scheme 9 . 


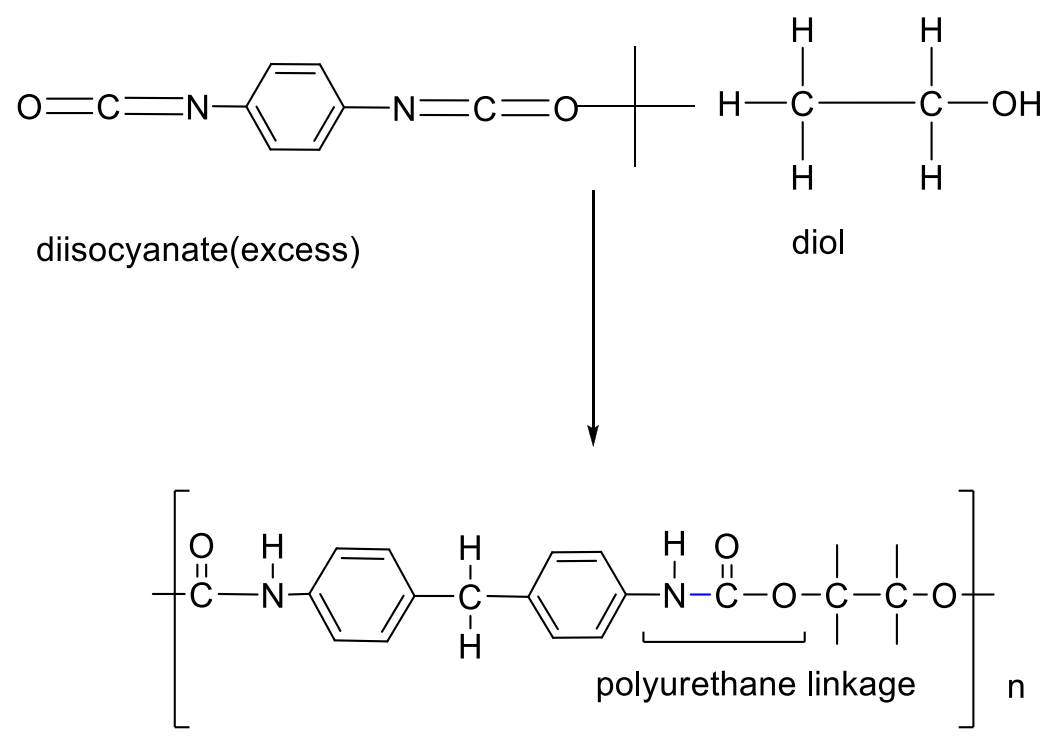

Polyurethane

Scheme 9: Synthesis of polyurethane from a diisocyanate and a diol. To cap this polymer, chain extenders of either diols or diamines can be added in order to tailor the properties

Uses of biodegradable plastics

Table 1:

\begin{tabular}{|c|c|c|}
\hline S. N. & Plastics: & Uses \\
\hline 1 & Polyglycolic acid & $\begin{array}{l}\text { Specialized applications; controlled drug releases; (PGA) } \\
\text { implantable composites; bone fixation parts. }\end{array}$ \\
\hline 2 & $\begin{array}{l}\text { Polylactic acid } \\
\text { (PLA) }\end{array}$ & $\begin{array}{l}\text { Packaging and paper coatings; other possible } \\
\text { markets include sustained release systems for } \\
\text { pesticides \& fertilizers, mulch films, \& compost bags. }\end{array}$ \\
\hline 3 & $\begin{array}{l}\text { Polycaprolactone } \\
\text { (PCL) }\end{array}$ & $\begin{array}{l}\text { Long-term items; mulch and other agricultural films; fibers } \\
\text { containing herbicides to control aquatic weeds; seedling } \\
\text { containers; slow release systems for drugs. }\end{array}$ \\
\hline 4 & $\begin{array}{l}\text { Polyhydroxybutyrate } \\
\text { (PHB) }\end{array}$ & $\begin{array}{l}\text { Products like bottles, bags, wrapping film and disposable } \\
\text { nappies, as a material for tissue engineering scaffolds and for } \\
\text { controlled drug release carriers. }\end{array}$ \\
\hline 5 & $\begin{array}{l}\text { Polyhydroxyvalerate } \\
\text { (PHBV) }\end{array}$ & $\begin{array}{l}\text { Films and paper coatings; other possible markets include } \\
\text { biomedical applications, therapeutic delivery of worm } \\
\text { medicine for cattle, and sustained release systems for } \\
\text { pharmaceutical drugs and insecticides. }\end{array}$ \\
\hline 6 & $\begin{array}{l}\text { Polyvinyl alcohol } \\
\text { (PVOH) }\end{array}$ & $\begin{array}{l}\text { Packaging and bagging applications which dissolve in water } \\
\text { to release Products such as laundry detergent, pesticides, and } \\
\text { hospital washables. }\end{array}$ \\
\hline 7 & $\begin{array}{l}\text { Polyvinyl acetate } \\
\text { (PVAc) }\end{array}$ & $\begin{array}{l}\text { Adhesives, the packaging applications include boxboard } \\
\text { manufacture, paper bags, paper lamination, tube winding and } \\
\text { remoistenable labels. }\end{array}$ \\
\hline
\end{tabular}




\section{Biodegradation of Plastics}

Microorganisms such as bacteria and fungi are concerned in the degradation of both natural and synthetic plastics [10]. The biodegradation of plastics proceeds vigorously under different soil conditions according to their properties, because the microorganisms responsible for the degradation differ from each other and they have their own most favorable growth conditions in the soil. Polymers especially plastics are potential substrates for heterotrophic microorganisms [10]. Biodegradation is governed by different factors that include polymer characteristics, type of organism, and nature of pretreatment. The polymer characteristics such as its mobility, tacticity, crystallinity, molecular weight, the type of functional groups and substituents present in its structure, and plasticizers or additives added to the polymer all play an important role in its degradation [10]. During degradation the polymer is first changed to its monomers, then these monomers are mineralized. Most polymers are too large to pass through cellular membranes, so they must first be de-polymerized to smaller monomers before they can be absorbed and biodegraded within microbial cells. The initial breakdown of a polymer can result from a variety of physical and biological forces [10]. Physical forces, such as heating/cooling, freezing/thawing, or wetting/drying, can cause mechanical spoil such as the cracking of polymeric materials [10]. The growth of many fungi can also cause small-scale swelling and bursting, as the fungi penetrate the polymer solids [10]. Synthetic polymers, such as poly (caprolactone) [10], are also depolymerized by microbial enzymes, after which the monomers are absorbed into microbial cells and biodegraded [10]. Abiotic hydrolysis is the most important reaction for initiating the environmental degradation of synthetic polymers [10] like poly-carboxylates [10], poly (ethylene tere-phthalate) [10], polylactic acids and their copolymers [10], poly ( $\alpha$-glutamic acids) [10], and poly-dimethyl-siloxanes, or silicones [10]. Generally, an increase in molecular weight results in a decline of polymer degradability by microorganisms. In distinction, monomers, dimers, and oligomers of a polymer's repeating units are much easily degraded and mineralized. High molecular weights result in a spiky decrease in solubility making them critical for microbial attack because bacteria require the substrate to be assimilated through the cellular membrane and then further degraded by cellular enzymes. At least two categories of enzymes are actively involved in biological degradation of polymers: extracellular and intracellular de-polymerases [10]. During degradation, exo-enzymes from microorganisms rupture down complex polymers yielding smaller molecules of short chains, e.g., oligomers, dimers, and monomers, that are smaller enough to pass the semi-permeable outer bacterial membranes, and then to be utilized as carbon and energy sources. The process is called de-polymerization. When the end products are $\mathrm{CO}_{2}, \mathrm{H}_{2} \mathrm{O}$, or $\mathrm{CH}_{4}$, the degradation is called mineralization [10]. It is important to note that bio-deterioration and degradation of polymer substrate can rarely reach $100 \%$ and the reason is that a small segment of the polymer will be incorporated into microbial biomass, humus and other natural products [10]. Dominant groups of micro-organisms and the degradative pathways associated with polymer degradation are often determined by the environmental conditions. When $\mathrm{O}_{2}$ is available, aerobic micro-organisms are mostly responsible for damage of complex materials, with microbial biomass, $\mathrm{CO}_{2}$, and $\mathrm{H}_{2} \mathrm{O}$ as the final products. In contrast, under anoxic conditions, anaerobic consortium of microorganisms are responsible for polymer deterioration. The primary products will be microbial biomass, $\mathrm{CO}_{2}, \mathrm{CH}_{4}$ and $\mathrm{H}_{2} \mathrm{O}$ under methanogenic (anaerobic) conditions [10] (e.g. landfills/compost) (Fig. 4). The list of different micro-organisms degrading different groups of plastics is given in Table 2; [10]. 
Table 2: List of different microorganisms reported to degrade different types of plastics

\begin{tabular}{|c|c|c|c|}
\hline S. N. & Synthetic Plastics & Microorganism & Reference \\
\hline 1 & Polyethylene & $\begin{array}{l}\text { Brevibacillus borstelensis } \\
\text { Rhodococcus rubber } \\
\text { Penicillium } \\
\text { simplicissimumYK }\end{array}$ & $\begin{array}{l}\text { Hadad et al. (2005) } \\
\text { Sivan et al. (2006); } \\
\text { Gilan et al.,2004 } \\
\text { Yamada-Onodera et }\end{array}$ \\
\hline 2 & Polyurethane & $\begin{array}{l}\text { Comamonas acidovorans } \\
\text { TB-35 } \\
\text { Curvularia senegalensis } \\
\text { Fusarium solani } \\
\text { Aureobasidium pullulans } \\
\text { Cladosporium sp. } \\
\text { Pseudomonas chlororaphis }\end{array}$ & $\begin{array}{l}\text { Akutsu et al., } 1998 \\
\text { Howard (2002) } \\
\text { Zheng et al. (2005) }\end{array}$ \\
\hline 3 & Polyvinyl chloride & $\begin{array}{l}\text { Pseudomonas putida AJ } \\
\text { Ochrobactrum TD } \\
\text { Pseudomonas fluorescens } \\
\text { B- } 22 \\
\text { Aspergillus niger } \\
\text { van Tieghem F-1119 }\end{array}$ & $\begin{array}{l}\text { Anthony et al. } \\
\text { (2004) } \\
\text { Mogil 'nitskii et al. } \\
\text { (1987) }\end{array}$ \\
\hline & & Plasticized & \\
\hline 1 & $\begin{array}{l}\text { Polyvinyl Chloride } \\
\text { BTA-copolyester }\end{array}$ & $\begin{array}{l}\text { Aureobasidium pullulans } \\
\text { Thermomonspora } \\
\text { Fusca }\end{array}$ & $\begin{array}{l}\text { Webb et al. (2000) } \\
\text { Kleeberg et al. } \\
(1998)\end{array}$ \\
\hline & & Natural plastics & \\
\hline 1 & $\begin{array}{l}\text { Poly(3-hydroxybutyrate-co-3- } \\
\text { mercaptopropionate) }\end{array}$ & $\begin{array}{l}\text { Schlegelella } \\
\text { thermodepolymerans }\end{array}$ & Elbanna et al. (2004) \\
\hline 2 & Poly(3-hydroxybutyrate) & Pseudomonas lemoignei & $\begin{array}{l}\text { Jendrossek et al. } \\
\text { (1995) }\end{array}$ \\
\hline 3 & $\begin{array}{l}\text { Poly (3-hydroxybutyrate-co- 3- } \\
\text { mercaptopropionate) }\end{array}$ & Pseudomonas indica $\mathrm{K} 2$ & Elbanna et al. (2004) \\
\hline 4 & $\begin{array}{l}\text { Poly(3-hydroxybutyrate) } \\
\text { Poly (3-hydroxybutyrate-co- 3- } \\
\text { hydroxyvalerate) }\end{array}$ & Streptomyces sp. SNG9 & $\begin{array}{l}\text { Mabrouk and Sabry } \\
(2001)\end{array}$ \\
\hline 5 & $\begin{array}{l}\text { Poly (3-hydroxybutyrate-co- 3- } \\
\text { hydroxypropionate) }\end{array}$ & Ralstonia pikettii T1 & \\
\hline 6 & $\begin{array}{l}\text { Poly(3-hydroxybutyrate-co- 3- } \\
\text { hydroxypropionate) }\end{array}$ & Acidovorax sp. TP4 & Wang et al. (2002) \\
\hline 7 & $\begin{array}{l}\text { Poly(3-hydroxybutyrate) } \\
\text { poly(3-hydroxypropionate) } \\
\text { poly(4-hydroxybutyrate) } \\
\text { poly(ethylene succinate) } \\
\text { poly(ethylene adipate) }\end{array}$ & $\begin{array}{l}\text { Alcaligenes faecalis } \\
\text { Pseudomonas stutzeri } \\
\text { Comamonas acidovorans }\end{array}$ & Kasuya et al. (1999) \\
\hline 8 & Poly(3-hydroxybutyrate) & Alcaligenes faecalis & Kita et al. (1997) \\
\hline
\end{tabular}




\begin{tabular}{|l|l|l|l|}
\hline 9 & Poly(3-hydroxybutyrate) & $\begin{array}{l}\text { Schlegelella } \\
\text { Thermodepolymerans } \\
\text { Caenibacterium } \\
\text { thermophilum }\end{array}$ & Romen et al. (2004) \\
\hline 10 & $\begin{array}{l}\text { Poly(3-hydroxybutyrate-co-3- } \\
\text { hydroxyvalerate) }\end{array}$ & $\begin{array}{l}\text { Clostridium botulinum } \\
\text { Clostridium } \\
\text { acetobutylicum }\end{array}$ & $\begin{array}{l}\text { Abou-Zeid et al. } \\
\text { (2001) }\end{array}$ \\
\hline 11 & Polycaprolactone & $\begin{array}{l}\text { Clostridium botulinum } \\
\text { Clostridium } \\
\text { acetobutylicum }\end{array}$ & $\begin{array}{l}\text { Abou-Zeid et al. } \\
\text { (2001) }\end{array}$ \\
\hline 12 & Polycaprolactone & Fusarium solani & Benedict et al., 1983 \\
\hline 13 & Polylactic acid & $\begin{array}{l}\text { Fusarium moniliforme } \\
\text { Penicillium roquefort } \\
\text { Amycolatopsis sp. } \\
\text { Bacillus brevis } \\
\text { Rhizopus delemer }\end{array}$ & $\begin{array}{l}\text { Torres et al., 1996 } \\
\text { Pranamuda et } \\
\text { al,1997 } \\
\text { Pranamuda and } \\
\text { Tokiwa, 1999 } \\
\text { Tomita et al., 1999 } \\
\text { Fukuzaki et al.,1989 }\end{array}$ \\
\hline 1 & Starch/polyethylene & $\begin{array}{l}\text { Polymer blends } \\
\text { Aspergillus niger } \\
\text { Penicillium funiculosm } \\
\text { Phanerochaete } \\
\text { chrysosporium }\end{array}$ & $\begin{array}{l}\text { Streptomyces } \\
\text { Phanerochaete } \\
\text { chyrsosporium }\end{array}$ \\
\hline 2 & Starch/polyester & Lee et al., 1991 \\
\hline & & Lee et al., 1991 \\
\hline
\end{tabular}

\subsection{Biodegradation of Natural Plastics}

\subsubsection{Biodegradation of Polyhydroxyalkanoates}

Microorganisms that produce and store PHA under nutrient limited conditions may degrade and metabolize it when the limitation is uninvolved [10]. However, the ability to store PHA does not necessarily guarantee the ability to degrade it in the environment [10]. Individual polymers are much too large to be transported directly across the bacterial cell wall. Therefore, bacteria must have evolved extracellular hydrolyses capable of converting the polymers into corresponding hydroxyl acid monomers [10]. The product of PHB hydrolysis is R-3-hydroxyl butyric acid, while extracellular degradation of PHBV yields both 3-hydroxybutyrate and 3- hydroxyl valerate [10]. The monomers are water soluble but small enough to passively circulate through the cell wall, where they are metabolized by $\beta$-oxidation and tri-carboxylic acid cycle (TCA) to produce carbon dioxide and water under aerobic conditions [10]. Under anaerobic conditions, methane is also produced [10]. In general, no damaging intermediates or by-products are generated during PHA degradation. In fact, 3-hydroxybutyrate is found in all higher animals as blood plasma [10]. For this reason, PHAs have been considered for medical applications, including long-term controlled drug release, surgical pins, sutures, and bone and blood vessel replacement. A number of aerobic and anaerobic micro-organisms that degrade PHA, particularly bacteria and fungi, have been 
isolated from various environments [10]. Acidovorax faecilis, Aspergillus fumigatus, Comamonas sp., Pseudomonas lemoignei and Variovorax paradoxus are among those found in soil, while in activated sludge Alcaligenes faecalis and Pseudomonas have been isolated. Comamonas testosteroni has been found in seawater, Ilyobacter delafieldii is present in the anaerobic sludge. PHA degradation by Pseudomonas stutzeri in lake water has also been observed. Because a microbial environment is required for degradation, PHA is not affected by moisture alone and is indefinitely stable in air [10].

PHAs have attracted industrial attention for use in the production of biodegradable and biocompatible thermoplastics [10]. Poly (3-hydroxybutyrate) (PHB) and Poly (3-hydroxybutyrateco-3-hydroxyvalerate) degrading organisms were isolated from sewage sludge and evaluated their competence to degrade PHB and PHBV in solid-plate assay. They have isolated a Strepto-myces strain, identified as Strepto-verticillium kashmeriense AF1, capable of degrading PHB and PHBV, and a bacterial strain Bacillus megaterium AF3, capable of degrading PHBV, from the soil mixed with active sewage mud on the basis of producing clear zones of hydrolysis on PHB and PHBV containing mineral salt agar plates [10]. The microbial degradation rate of poly (3hydroxybutyrateco- 3-hydroxyvalerate) (PHBV) films in soil appeared to be dependent on the microbial population and distribution, and the degradation ability of the PHBV-degrading microorganisms colonizing the surface of incubated PHBV films [10]. In one of our studies, the scanning electron micrographs of the PHBV film buried in soil mixed with sewage sludge for 120 days showed clear evidences of degradation with pits, surface roughening, grooves, cavities and disintegration (Fig. 4). Later on S. kashmirense AFl was recovered from the surface of PHBV film. Sang et al. (2002) also reported various traces, cavities, and grooves as observed on the injured surface of PHBV films demonstrating that the degradation was a concerted effect of a microbial consortium colonizing the film surface, including fungi, bacteria, and action-mycetes. Numerous irregular corrosion pits have also been observed by Molitoris et al. (1996) on the surface of poly polyhydroxyalkanoate by Comamonas $s p$. Sturm test has been used by many researchers to study the biodegradation of biodegradable polymers [10], the aliphatic and aromatic compounds [10]. We have gravimetrically calculated $\mathrm{CO}_{2}$ evolved as a result of PHB and PHBV biodegradation by $S$. kashmirense $A F 1$ and $B$. megaterium $A F 3$, through Sturm Test. The results showed that in all the cases the amount of $\mathrm{CO}_{2}$ evolved in test was more than in control [10].

\subsubsection{Enzymatic Degradation of Polyhydroxalkanoates}

At least two categories of enzymes are actively involved in biological degradation of polymer: extracellular and intracellular de-polymerases [10]. Extracellular PHB de-polymerases are secreted from various microorganisms and play an significant role in the metabolism of PHB in the environment. Several PHB de-polymerases have been remote and purified from various microorganisms belonging to the Alcaligenes [10], Comamonas [10] and Pseudomonas species [10]. This shows that extracellular PHB de-polymerases are everywhere in the environment. Analysis of their primary structures revealed that the enzymes are composed of substrate-binding area, catalytic area, and a linker region connecting the two area. The substrate-binding domain plays a role in binding to the solid PHB. The catalytic domain contains the catalytic machinery composed of a catalytic triad (Ser-His-Asp). The serine is part of a lipase box penta-peptide Gly$\mathrm{X}-\mathrm{Ser}-\mathrm{X}-\mathrm{Gly}$, which has been found in all known hydrolases such as lipases, esterase's and serine proteases. The properties of PHB de-polymerases have been studied extensively and share several 
biochemical properties such as: relatively small molecular weight, below $100 \mathrm{kDa}$ and most PHA de-polymerases are between 40 and $50 \mathrm{kDa}$; do not bind to anion exchangers such as DEAE but have strong affinity to hydrophobic materials such as butyl-Toyopearl and phenyl-Toyopearl; optimum $\mathrm{pH}$ is between 7.5-9.8, only the de-polymerase of Pseudomonas picketti and Penicillium funiculosum have $\mathrm{pH}$ optima between 5.5 and 7; highly stable at a wide range of $\mathrm{pH}$, temperature, ionic strength, etc; most PHA de-polymerases are inhibited by serine esterase inhibitors such as diidopropyl-fluoryl-phosphate or acylsulfonyl compounds, which have been exposed to bind covalently to the active place serine of serine hydrolases [10]. In 1990 the British-based company imposing Chemical Industries (ICI) released a material called Biopol. Biopol is made from PHBV. When fearful away, this material is broken down by the microorganisms present in waste and decomposed completely within a couple of months. Other versions of biodegradable plastics have been developed in the United States. In 1991 Procter and Gamble, Du Pont, and Exxon funded bacteria-based plastic research at the University of Massachusetts at Amherst. In addition, Battelle, a private research company, produced a completely biodegradable plastic from vegetable oils. Plastics can be made from other glucoseintensive materials such as potato scraps, corn, molasses, and beets [10]. By 1997, compostable bags still sold for more than non-degradable bags. One synthetic polymer used in biodegradable plastic bags was aliphatic polyester called polycaprolactone, marketed by Union Carbide. Another biodegradable plastic film called Mater Bi contained corn starch and other proprietary ingredients. Corn was also used to make poly-lactic acid for Cargill's Eco-PLA biopolymer. University of Michigan worked on a material called Envar consisting of an alloy of capro-lactone and a thermoplastic starch. One research group at the University of Utah at Salt Lake City in 1997, for instance, synthesized an injectable polymer that forms a non-toxic biodegradable hydro gel that acts as a sustained release matrix for drugs [10].

\section{Biodegradation of Synthetic Plastics}

The degradation of most synthetic plastics in nature is a very slow process that involves environmental factors, followed by the action of wild microorganisms [10]. The primary mechanism for the biodegradation of high molecular weight polymer is the oxidation or hydrolysis by enzyme to create functional groups that improves its hydro-phylicity. Consequently, the main chains of polymer are degraded resulting in polymer of low molecular weight and feeble mechanical properties, thus, making it more accessible for further microbial assimilation [10]. Examples of synthetic polymers that biodegrade include poly (vinyl alcohol), poly (lactic acid), aliphatic polyesters, poly-caprolactone, and polyamides. Several oligomeric structures which biodegrade are known: oligomeric ethylene, styrene, isoprene, butadiene, acrylonitrile, and acrylate. Physical properties such as crystallinity, orientation and morphological properties such as surface area, affect the rate of degradation [10].

\subsection{Biodegradation of Thermoplastic Polyolefin's}

\subsubsection{Polyethylene}

Synthetic poly-olefins are inert materials whose backbones consist of only long carbon chains. The characteristic structure makes poly-olefins non-susceptible to degradation by microorganisms. However, a comprehensive study of polyolefin biodegradation has shown that some microorganisms could utilize poly-olefins with low molecular weight [10]. The biodegradation 
always follows photo degradation and chemical degradation. Polyethylene is one of the synthetic polymers of high hydrophobic level and high molecular weight. In natural form, it is not biodegradable. Thus, their use in the production of disposal or packing materials causes dangerous environmental problems. To make PE biodegradable requires modifying its crystalline level, molecular weight and mechanical properties that are responsible for PE resistance towards degradation [10]. This can be achieved by improving PE hydrophilic level and/or reducing its polymer chain length by oxidation to be accessible for microbial degradation [10]. The degradation of polyethylene can occur by different molecular mechanisms; chemical, thermal, photo and biodegradation. Some studies [10] have assessed the biodegradability of some of these new films by measuring changes in physical properties or by observation of microbial growth after exposure to biological or enzymatic environments, but mostly by $\mathrm{CO}_{2}$ evolution. Since polyethylene (PE) is widely used as packaging material, considerable work not only on biodegradable polyethylene but also on biodegradation of polyethylene has been conducted [10]. The results of these studies indicated that polyethylene was biodegraded following photo degradation and/or chemical degradation. Biodegradation of polyethylene is known to occur by two mechanisms: hydrobiodegradation and oxo-biodegradation [10]. These two mechanisms agree with the modifications due to the two additives, starch and pro-oxidant, used in the synthesis of biodegradable polyethylene. Starch blend polyethylene has a continuous starch phase that makes the material hydrophilic and therefore, catalyzed by amylase enzymes. Microorganisms can easily access, attack and remove this part. Thus the hydrophilic polyethylene with matrix continues to be hydrobiodegraded. In case of pro-oxidant additive, biodegradation occur following photo degradation and chemical degradation. If the pro-oxidant is a metal combination, after transition, metal catalyzed thermal per-oxidation, biodegradation of low molecular weight oxidation products occurs sequentially [10]. EI-Shafei et al. (1998) investigated the ability of fungi and Strepto-myces strains to attack degradable polyethylene consisting of disposed polyethylene bags containing $6 \%$ starch. He has isolated 8 different strains of Strepto-myces and two fungi Mucor rouxii NRRL 1835 and Aspergillus flavus. In a study, Low density polyethylene pieces buried in soil mixed with sewage sludge were examined microscopically after 10 months, fungal attachment was found on the surface of the plastic, indicating possible utilization of plastic as a source of nutrient (Shah, 2007) The isolated fungal strains were identified as Fusarium sp. AF4, Aspergillus terreus AF5 and Penicillum sp. AF6. The ability of the fungal strains to form a bio-film on polyethylene was attributed to the gradual decrease in hydro-phobicity of its surface [10]. The structural changes in the form of pits and erosions observed through scanning electron-microscopy indicated surface damage of PE incubated with Fusarium sp. AF4. That suggested that the fungal strains, especially Fusarium sp. AF4, was able to adhere to the surface of LDPE and can cause surface damage [10]. In a study by Bonhomme et al. (2003), SEM evidence confirmed that microorganisms (fungi) build up on the surface of the polymer (polyethylene) and after removal of the micro-organisms, the surface became physically pitted and eroded. The surface of the polymer after biological attack was physically weak and readily disintegrates under mild pressure. Otake et al. (1995) reported the changes like whitening of the degraded area and small holes on the surface of PE film after soil burial for 32 years. Biodegradation of LDPE film was also reported as $0.2 \%$ weight loss in 10 years. Ohtaki et al. (1998) tested LDPE bottles exposed in aerobic soil for over 30 years, and observed some evidences of biodegradation using SEM of the degraded parts and as reduction in molecular weight by Time of Flight Mass Spectrometry (TOF-MS). Yamada-Onodera et al. (2001) isolated a strain of fungus Penicillium simplicissimum YK to biodegrade polyethylene without additives. UV light or oxidizing agents, such as UV sensitizer, were used at the beginning of the 
process to activate an inert material, polyethylene. Polyethylene was also treated with nitric acid at $80{ }^{\circ} \mathrm{C}$ for 6 days before cultivation with inserted functional groups that were susceptible to microorganisms. Bonhomme et al. (2003) has reported that with the fungal activity, polyethylene with a starting molecular weight in the range of 4000 to 28,000 was degraded to units with a lower molecular weight of 500 after three months of liquid cultivation, which indicated the biodegradation of that polyethylene. In a similar study the Polyethylene pieces were treated by exposing it to UV light and also nitric acid. That pretreated polymer was then applied to microbial treatment using Fusarium sp. AF4 in a mineral salt medium containing treated plastic as a sole source of carbon and energy. An increase in the growth of fungus and some structural changes as observed by FTIR, were observed in case of treated PE which according to Jacinto indicated the breakdown of polymer chain and presence of oxidation products of PE. Non-degraded polyethylene exhibits almost zero absorbancy at those wave numbers [10]. Absorbance at 1710$1715 \mathrm{~cm}^{-1}$ (corresponding to carbonyl compound), $1640 \mathrm{~cm}-1$ and $830-880 \mathrm{~cm}^{-1}$ (corresponding to $-\mathrm{C}=\mathrm{C}-$ ), which appeared after $\mathrm{UV}$ and nitric acid treatment, decreased during cultivation with microbial consortia [10]. Typical degradation of PE and formation of bands at 1620- $1640 \mathrm{~cm}^{-1}$ and 840-880 $\mathrm{cm}^{-1}$ was also reported by Yamada- Onodera et al. (2001), attributed to oxidation of polyethylene. Overall, polyethylene degradation is a combined photoand bio-degradation process. First, either by abiotic oxidation (UV light exposure) or heat treatment, essential abiotic precursors are obtained. Secondly, selected thermophilic microorganisms degrade the low molar mass oxidation products to complete the biodegradation [10].

\subsubsection{Polyvinyl Chloride}

Polyvinyl chloride (PVC) is a strong plastic that resists abrasion and chemicals and has low moisture absorption. Mostly, PVC is used in buildings for pipes and fittings, electrical wire insulation, floor coverings and synthetic leather products. It is also used to make shoe soles, rigid pipes, textiles and garden hoses. There are many studies about thermal and photo-degradation of PVC [10] but there only few reports available on biodegradation of PVC. According to Kirbas et al. (1999) PVC having low molecular weight can be exposed to biodegradation by the use of whiterot fungi.

\subsubsection{Polystyrene}

Polystyrene (PS) is a synthetic plastic used in the production of disposable cups, packaging materials, in laboratory ware, in certain electronic uses. PS is used for its lightweight, stiffness and excellent thermal insulation. When it is degraded by thermal or chemical means it releases products like; styrene, benzene, toluene and acrolein. There are very few reports on the biodegradation of polystyrene but the microbial decomposition of its monomer; styrene, have been reported by few researchers [10].

\section{Biodegradation of Polymer Blends}

The rate of degradation of polymer blends is initially controlled by the degradation of the more readily biodegradable component. The initial degradation process interferes with the structural integrity of the polymer and increases the surface area considerably for enzyme attack on the less 
affected area. The exposure of the remaining polymer to microbes and secreted degradative enzymes is then enhanced. Work has been carried out to understand the degradation mechanisms of different polymer blends and their degradation products by microorganisms. There are several categories of biodegradable starch-based polymers including:

1) Thermoplastic starch products;

2) Starch synthetic aliphatic polyester blends;

3) Starch PBS/PBSA polyester blends; and

4) Starch PVOH blends.

\subsection{Starch/Polyethylene Blends}

Polyethylene is reported to be an inert polymer with strong resistance to microbial breakdown [10]. Biodegradation is decreased with an increase in molecular size. Linear paraffin molecules below a molecular size of about $500 \mathrm{Da}$ can be utilised by several microorganisms [10]. Scott (1990) concluded that microbial attack on polyethylene is a secondary process where an initial oxidation step results in the reduction of molecular size to a size sufficiently small for biodegradation to occur. Addition of readily biodegradable compounds, such as starch, to a low-density polyethylene matrix may enhance the degradation of the carbon-carbon backbone [10]. The biodegradability of starch/polyethylene blends, and chemically modified samples of blends has been investigated [10]. The aerobic and anaerobic biodegradability of starch-filled polymer blends has been evaluated. Carbon removal from a starch polyethylene blend was low compared to pure starch and the rate of removal was higher under aerobic conditions. Similar results were obtained by Chandra and Rustgi (1997) for the biodegradation of maleated linear low-density polyethylene starch blends in a soil environment composed of a mixed fungal inoculums consisting of Aspergillus niger, Penicillium funiculom, Chaetomium globosum, Gliocladium virens and Pullularia pullulans. Biodegradation of starch polyethylene films containing a pro-oxidant and 6\% starch showed evidence of polyethylene degradation in the presence of lignin degrading bacteria of the genus Strepto-myces and also in the presence of the white-rot fungus Phanerochaete chrysosporium [10]. The rate of degradation of starch-filled polyethylene depended on the starch content, and was very sensitive to the environmental conditions and other ingredients in the formulation [10]. Oxidation of impurities, such as fats and oils, would seem to be an important trigger for the biodegradation of polyethylene. The production of reactive oxygen species such as peroxides is a likely source of initiators of molecular breakdown although other radicals may be involved [10]. The degradation of 11 commercially produced degradable starch/polyethylene blended compost bags was evaluated in a municipal yard waste compost site [10] by chemical degradation, photo-degradation and biodegradation of each product. The oxygen concentration at the surface of the films appeared to be the rate-limiting component. A pro-oxidant additive (transition metal) was critical in promoting the oxidative degradation of the polyethylene. Several researchers have investigated the use of modified starch in starch/low density polyethylene blends [10]. The modified starches enhanced the miscibility and adhesion of starch in those blends. However, the poor biodegradability of modified starches leads to a very slow rate of biodegradation compared with unmodified starch/polyethylene blends. Other investigations have been carried out to evaluate the biodegradability of films containing starch, polyethylene and EAA [10]. The results indicated that rapid and appreciable starch depletion led to deterioration of the mechanical properties of the films leaving a rather weak matrix which was prone to further physical disruption by biotic and abiotic factors. 


\subsection{Starch/Polyester Blends}

Blends of starch and Poly-caprolactone (PCL) are assumed to be completely biodegradable since each component in the blend is readily biodegradable as well as compostable [10]. Biodegradability of different grades of the commercial polyester Bionolle ${ }^{\mathrm{TM}}$ has been studied in activated sludge, soils and compost [10]. Bionolle ${ }^{\mathrm{TM}} 3000$ was degraded more easily than Bionolle 1000 and Bionolle ${ }^{\mathrm{TM}} 6000$. Moulds did not degrade Bionolle ${ }^{\mathrm{TM}} 6000$ and some Gramnegative bacteria did not degrade Bionolle ${ }^{\mathrm{TM}} 1000$. The degree of degradation mainly depended on the type of microorganism and their population. It is known that poly-(hydroxybutyrate) depolymerases and lipases are both capable of cleaving the ester bonds 4 poly-(hydroxyalkanoate). Because of structural similarity, these enzymes are expected to degrade Bionolle ${ }^{\mathrm{TM}}$. Biodegradation of Bionolle ${ }^{\mathrm{TM}}$ by compost has been studied and shown to be complete [10]. Furthermore, the products were shown to be non-toxic to the earthworm, Eisena fetida. Blending of Bionolle with low cost starch has been investigated in order to improve its cost competitiveness even as maintaining other properties at an acceptable level. It has been shown that the addition of starch filler significantly improved the rate of degradation of the Bionolle ${ }^{\mathrm{TM}}$ component [10]. A study of the biodegradation of cellulose, a poly(-caprolactone) starch blend and an aliphaticaliphatic co-polyester was undertaken in a ring test [10] involving several laboratories using standards like; ISO 14852 (1999), and ISO 14852. According to both criterion (the biological oxygen demand (BOD) and $\mathrm{CO}_{2}$ released) the cellulose was more degraded than the poly(caprolactone)-starch blend which in turn was more degraded (on average) than the co-polyester.

\subsection{Starch/PVA Blends}

The water-soluble synthetic polymer, polyvinyl alcohol (PVA) has excellent compatibility with starch and blends are expected to have good film properties. Several such blends have been developed and tested for biodegradable packaging applications and appear to have potential for use [10]. PVA and starch blends are assumed to be biodegradable since both components are biodegradable in various microbial environments. The processing and mechanical properties of starch/PVA blends have been well investigated [10] but only a limited number of publications are available regarding the biodegradability of such blends. Data on the biodegradability of starch, PVA, glycerol and urea blends by bacteria and fungi isolated from the activated sludge of a municipal sewage plant and landfill indicated that microorganisms consumed starch and the amorphous region of PVA as well as the glycerol and urea plasticiser's [10]. The crystalline region of PVA was unaffected. A biodegradability study of starch, PVA and glycerol blends has also been carried out by Park et al. (1994). ASTM D 5271-92 (1992) was used to evaluate the rate and degree of biodegradation of PVA blends which were reported as biodegradable. In a part study of PVA and poly- (3-hydroxybutyric acid) blended films, the solubility of the PVA component in water was found to effect the biodegradability of the blend [10].

\subsection{Poly-Lactic Acid (PLA) (Renewable Resource) Polyesters}

Poly-lactic acid (PLA) is linear aliphatic polyester produced by poly-condensation of naturally produced lactic acid or by the catalytic ring opening of the lactide group. Lactic acid is produced (via starch fermentation) as a co-product of corn wet milling. The ester linkages in PLA are sensitive to both chemical hydrolysis and enzymatic chain cleavage. PLA is frequently blended 
with starch to increase biodegradability and reduce costs. However, the brittleness of the starchPLA blend is a major drawback in many applications. To remedy this limitation, a number of low molecular weight plasticizers such as glycerol, sorbitol and triethyl citrate are used. A number of companies produce PLA, such as Cargill Dow LLC. PLA produced by Cargill Dow was originally sold under the name Eco PLA, but now is known as Nature Works PLA, which is actually a family of PLA polymers that can be used alone or blended with other natural-based polymers (Developing Products that Protect the Environment, 2007). The applications for PLA are thermoformed products such as drink cups, take-away food trays, containers and planter boxes. The material has good rigidity characteristics, allowing it to replace poly-stryene and PET in some applications. PLA is fully biodegradable when composted in a large-scale operation with temperatures of $60{ }^{\circ} \mathrm{C}$ and above. The first stage of degradation of PLA (two weeks) is via hydrolysis to water-soluble compounds and lactic acid. Rapid metabolisation of these products into $\mathrm{CO}_{2}$, water and biomass by a variety of microorganisms. There have been reports on the degradation of PLA oligomers (molecular weight $\sim 1000$ ) by Fusarium moniliforme and Penicillium Roquefort [10] and the degradation of PLA by Amycolatopsis sp. [10] and by Bacillus brevis. In addition, enzymatic degradation of low molecular weight PLA (molecular weight 2000) has been shown using esterase-type enzymes such as Rhizopus delemer lipase [10]. McCarthy (1999) showed that APLA presents a soil degradation rate much slower compared to PBSA.

\subsection{Poly-Butylene Succinate (PBS) (Synthetic Aliphatic) Polyesters}

Poly-butylene succinate (PBS) is a biodegradable synthetic aliphatic polyester with similar properties to PET. PBS is generally blended with other compounds, such as starch (TPS) and adipate copolymers (to form PBSA), to make its use economical. PBS has excellent mechanical properties and can be applied to a range of end applications via conventional melt processing techniques. Applications include mulch film, packaging film, bags and 'flushable' hygiene products. PBS is hydro-biodegradable and begins to biodegrade via a hydrolysis mechanism. Hydrolysis occurs at the ester linkages and this results in a lowering of the polymer's molecular weight, allowing for further degradation by microorganisms. Data from SK Chemicals (Korea), a leading manufacturer of PBS polymers, quotes a degradation rate of 1 month for $50 \%$ degradation for $40 \mu \mathrm{m}$ thick film in garden soil.

\subsection{Aliphatic-Aromatic (Aac) Co-Polyesters}

Aliphatic-aromatic (AAC) co-polyesters combine the biodegradable properties of aliphatic polyesters with the strength and performance properties of aromatic polyesters. This class of biodegradable plastics is seen by many to be the answer to making fully biodegradable plastics with property profiles similar to those of commodity polymers such as polyethylene. To reduce cost AACs are often blended with TPS. Although AACs have obvious benefits, their market potential may be affected by legislation, such as that in Germany, which distinguishes between biodegradable plastics made from renewable resources and those, like AAC, which use basically the same raw materials as commodity plastics and petrochemicals.

Currently in Germany, biodegradable plastics must contain greater than 50\% renewable resources to be accepted (Biodegradable Plastics-Developments and Environmental Impacts, 2002). The two main types of commercial AAC plastics are Eco flex ${ }^{\mathrm{TM}}$ produced by BASF and Eastar Bio ${ }^{\mathrm{TM}}$ 
produced by Eastman. Under each trade name are a number of specific grades. Each grade of polymer has been designed with controlled branching and chain lengthening to match its particular application. AACs come closer than any other biodegradable plastics to equalling the properties of low density polyethylene, especially for blown film extrusion. AACs also can meet all the functional requirements for cling film such as transparency, flexibility and anti-fogging performance, and therefore this material has great promise for use in commercial food wrap for fruit and vegetables, with the added advantage of being compostable. Whilst being fossil fuelbased, AACs are biodegradable and compostable. AACs fully biodegrade to carbon dioxide, water and biomass. Typically, in an active microbial environment the polymer becomes invisible to the naked eye within 12 weeks (Biodegradable Plastics-Developments and Environmental Impacts, 2002).

\subsection{Modified Polyethylene Tere-Phthalate (PET)}

Modified PET (polyethylene tere-phthalate) is PET which contains co-monomers, such as ether, amide or aliphatic monomers that provide 'weak' linkages that are susceptible to biodegradation through hydrolysis. The mechanism involves a combination of hydrolysis of the ester linkages and enzymatic attack on ether and amide bonds. With modified PET it is possible to adjust and control degradation rates by varying the co-monomers used. Depending on the application, up to three aliphatic monomers are incorporated into the PET structure. Typical modified PET materials include PBAT (polybutylene adipate/terephthalate) and PTMAT (polytetramethylene adipate/ terephthalate). DuPont have commercialised Biomax ${ }^{\mathrm{TM}}$ which is a hydro-biodegradable modified PET polyester. Certain Biomax ${ }^{\mathrm{TM}}$ grades also contain degradation promoters to provide tailored combinations of performance properties and degradation rates. The options available for modified PET provide the opportunity to produce polymers which specifically match arange of application physical properties whilst maintaining the ability to adjust the degradation rate by the use of copolyesters.

\section{Bio-Fragmentation}

Fragmentation is a lytic phenomenon necessary for the subsequent event called assimilation. A polymer is a molecule with a high molecular weight, unable to cross the cell wall and/or cytoplasmic membrane. It is indispensable to cleave several bonds to obtain a mixture of oligomers and/or monomers. The energy to accomplish scissions may be of different origins: thermal, light, mechanical, chemical and/or biological. The abiotic involvement was described previously. This section focuses on the biological aspect of fragmentation. Microorganisms use different modi operandi to cleave polymers. They secrete specific enzymes or generate free radicals. Enzymes are catalytic proteins that decrease the level of activation energy of molecules favouring chemical reactions. These proteins have a wide diversity and a remarkable specificity, but they are easily denatured by heat, radiations, surfactants, and so forth [10]. Endo-peptidase, endo-esterases achieve their catalyticaction along the polymer chain whereas exo-enzymes catalyse reactions principally at the edges. Constitutive enzymes are synthesized during all the cellular life, independently of the presence of specific substrates. Inducible enzymes are produced when a molecular signal due to the presence of a specific substrate is recognised by the cell. In this case, enzymes are not synthesized instantaneously but a latent period is necessary to establish the cell machinery. The concentration of inducible enzymes increases as a function of time and stops at 
substrate exhaustion. When released into the extracellular environment, enzymes can be found as free catalysts (i.e. soluble within aqueous or lipophilic media) or fixed on particles (e.g. soil organic matter, clays and sand). Fixed enzymes are stabilised and their catalytic activity is often increased. Moreover, they are also protected against autocatalytic denaturation (in particular proteases). The activity of concealed enzymes can continue even if the producer cells are dead. Enzymes are named and numbered (EC number) according to rules adopted by the Enzyme Commission of the International Union of a Pure and Applied Chemistry (IUPAC). The first number informs on the class of enzymes catalyzing a given chemical reaction:

1) Oxidoreductases

2) Transferases

3) Hydrolases

4) Lyases

5) Isomerases

6) Ligases (Weil, 1994)

\subsection{Enzymatic Hydrolysis}

Bio-fragmentation is mainly concerned by enzymes that belong to oxidoreductases and hydrolases. Cellulases, amylases and cutinases are hydrolases readily synthesised by soil microorganisms to hydrolyse natural abundant polymers (e.g. cellulose, starch and cutin). These polymers are, in some industrial composites, co-extruded with polyesters to increase the biodegradability [11]. Some enzymes with an activity of de-polymerisation of (co)polyesters have been identified [11]. They are lipases and esterases when they attack specifically carboxylic linkages and they are endopeptidases if the cleaved bond is an amide group.

\subsubsection{The Mechanism Described Underneath is an Illustration of a Bio-Fragmentation by Hydrolytic Enzymes: Polyester De-Polymerisation}

Studies on the biodegradation of bacterial polymers show that microorganisms secrete extracellular de-polymerases. The first discovery on the hydrolytic cleavage of a microbial polymer by specific enzymes was made on poly (hydroxyl-butyrate) (PHB). The name of these enzymes (PHB de-polymerases) was conserved even if these enzymes were found to be effective on the hydrolytic catalysis of other polyesters poly (propriolactone), poly (ethylene adipate), poly(hydroxyl-acetate), poly(hydroxyl-valerate), etc. [10]. However, in several studies on polyester biodegradation, some authors adopt another nomenclature, they use the abbreviated name of the polyester followed by "de-polymerase"; for instance, PBSA de-polymerase [11], enzyme fragmenting the poly (butylene succinate-co-butylene adipate); PCL de-polymerase [11], enzyme fragmenting the poly-(capro-lactone). A very common feature of hydrolases (e.g. depolymerases) is a reaction mechanism that uses three amino-acids residues: aspartate, histidine and serine (Fig. 4). Aspartate interacts with the histidine ring to form a hydrogen bond. The ring of histidine is thus oriented to interact with serine. Histidine acts as a base, deprotonating the serine to generate a very nucleophilic alkoxide group $(-\mathrm{O})$. Actually, it is this group that attacks the ester bond (the alkoxide group is a stronger nucleophile than an alcohol group) leading to the formation of an alcohol end group and an acyl-enzyme complex. Subsequently, water attacks the acylenzyme bond to produce a carboxyl end group and the free enzyme. This arrangement of serine, histidine and aspartate is termed as catalytic triad [11]. According to the microbial species, low 
molecular weight fragments can be metabolised or not. For instance, action-mycetes have a high potential for the de-polymerisation of polyesters, but they are not able to metabolise the formed products [11]. A complete polyester biodegradation would be the result of a microbial synergy.

\subsection{Enzymatic Oxidation}

When the scission reactions by specific enzymes are difficult (i.e. crystalline area, hydrophobic zones and stearic hindrances), other enzymes are implicated in the transformation of the molecular edifices. For instance, mono-oxygenases and di-oxygenases (i.e. oxidoreductases) incorporate, respectively, one and two oxygen atoms, forming alcohol or peroxyl groups that are more easily fragmentable. Other transformations are catalysed by per-oxidases leading to smaller molecules. They are hemo-proteins, enzymes containing a prosthetic group with an iron atom that can be electron donor or acceptor (i.e. reduced or oxidative form). Per-oxidases catalyse reactions between a peroxyl molecule (e.g. $\mathrm{H}_{2} \mathrm{O}_{2}$ and organic peroxide) and an electron acceptor group as phenol, phenyl, amino, carboxyl, thiol or aliphatic un-saturation [11]. A third group of oxidoreductases, named oxidases, are metallo-proteins containing copper atoms. They are produced by most lignolytic microorganisms. Two types of oxidases are well studied: one type catalyses hydroxylation reactions and the other one is involve in oxidation reactions [11]. Lignins are considered as three-dimensional natural polymers. Lignins are intemely associated to cellulose and hemicelluloses. This association gives a major role to lignin in the case on new materials using lingo-cellulosic sources, because lignin is a macromolecular framework difficult to degrade even by microorganisms, only lignolytic microorganisms can do it.

\subsubsection{To Illustrate Bio-Fragmentation by Oxidative Enzymes, the Lignin De- Polymerisation}

Lignolytic microorganisms synthesise enzymes able to cleave the complex macromolecular lignin network. Three main enzymes may be excreted: lignin peroxidase, manganese peroxidase and laccase [11]. They can act alone or synergistically [11], with different cofactors (e.g. iron, manganese_and copper). They can interact with low molecular weight_molecules [11], that could lead to the formation of free radicals and consequently to oxidise and to cleave of polylignols bonds [11].

\subsection{Radicalar Oxidation}

The addition of a hydroxyl function, the formation of carbonyl or carboxyl groups increases the polarity of the molecule. The augmentation of the hygroscopic character of the compound favors biological attack. Moreover, some oxidation reactions catalyzed by various enzymes produce free radicals conducing to chain reactions that accelerate polymer transformations. However, crystalline structures and highly organized molecular networks [11] are not favorable to the enzymatic attack, since the access to the internal part of these structures is extremely constrictive. Several soil decomposers, particularly brown-rot fungi, are able to produce $\mathrm{H}_{2} \mathrm{O}_{2}$ [11] that is an oxidative molecule very reactive allowing the enzymatic biodegradation of cellulose molecules. 


\subsubsection{The bio-fragmentation of cellulose by radicals is illustrated below}

Hydrogen peroxide produced by rot fungi reacts with ferrous atoms to perform the Fenton reaction [11].

$$
\mathrm{H}_{2} \mathrm{O}_{2}+\mathrm{Fe}^{2+}+\mathrm{H}^{+} \longrightarrow \mathrm{H}_{2} \mathrm{O}+\mathrm{Fe}^{3+}+\mathrm{OH}^{\bullet}
$$

The free radical $\mathrm{OH}$ is extremely reactive but non-specific. Fungi protect themselves against free radicals by the production of low molecular weight molecules that have a high affinity for these radicals. At present, this mechanism is not well understood; but these molecules seem to act as free radicals transporters. They easily diffuse throughout the medium where these radicals are reactivated to provoke polymer fragmentation. Kremer et al. (1993) have found that brown-rot fungi produce oxalate molecules able to diffuse within the cellulose fibres and chelate ferrous atoms. Hammel et al. (2002) have specified the involvement of a flavor-protein (cellobiose deshydrogenase) with a heme prosthetic group. Enoki et al. (1992) have isolated and purified an extracellular substance in Gloeophyllum trabeum cultures. This substance is a polypeptide named Gt factor, with oxido-reduction capacities and iron ions affinity [11]. If the mechanism of formation of free radicals is not well known, on the contrary, the mechanism of cellulose degradation by free radicals has been described by Hammel et al. (2002).

\subsection{How Can We Know If A Polymer Is Biofragmented?}

A polymer is considered as fragmented when low molecular weight molecules are found within the media. The most used analytical technique to separate oligomers with different molecular weight is the GPC, also called size exclusion chromatography (SEC) [11]. HPLC and GC are usually used to identify monomers and oligomers in a liquid [11] or in a gaseous phase [11]. After purification, intermediates molecules can be identified by MS. Monomer structures may be determined by NMR [11], functional chemical changes are easily detected by FTIR [11]. Some authors use enzymatic tests to estimate propensity for de-polymerising a given [11]. A simple method consists in mixing the polymer and an enzyme of specific activity within a liquid medium. The estimation of hydrolysis is determined by the appropriated techniques cited above. The so called "clear zone test" is a common method used to screen the microbial ability to hydrolyse a specific polymer. Very fine particles of a polymer and agar are dispersed within a hot synthetic medium. After cooling into Petri dishes, solid agar presents an opaque appearance. Subsequently, a microbial strain is inoculated and, after incubation, the formation of a clear halo around the microbial colony indicates the biosynthesis and the excretion of de-polymerases [11].

\section{Techniques Useful in Biodegradation Tracking and Biodegradable Polymers Characterization}

Knowledge on biodegradable polymers' structures is essential for the selection of such materials for specific applications. In recent years, much attention has been given to organic recycling of biodegradable polymeric materials, enabling the controlled biological decomposition of these polymers to products, which are safe and friendly to the environment and human life and health. Products made from biodegradable polymers after their disposal are subjected to organic recycling 
processes. This significantly reduces the environmental charge with waste, and allows for their rational utilization by industrial composting.

The precise characterization of polymers plays a crucial role in the selection of the proper materials for specific applications and allows to predict the behavior of the final product in the overall product life cycle.

In order to get their products certified as being biodegradable, producers have to perform biodegradation test of their products and/or materials in an accredited laboratory. These tests can be done at any stage of the product development process. The progress in (bio) degradation is determined by differential parameters such as macroscopic and microscopic changes in the polymer surface, changes in molar mass and weight loss and changes in microstructure. Appropriate measurements are performed using differential analytical techniques. The differential scanning calorimetry (DSC), the atomic force microscopy (AFM), the dynamic method of thermal analysis (DMA), gel permeation chromatography (GPC), and mass spectrometry (MS) as well as spectroscopy methods: nuclear magnetic resonance (NMR) and infrared absorption (IR), are used for observations of materials changes in the degradation process and complement each other. The NMR and IR spectroscopy allows to analyze polymeric materials' structures, and to track changes in the polymer chains microstructure due to the degradation process. Moreover the MS technique is used in the analysis of the oligomeric fraction formed during the degradation of the polymers [12].

The below presented fact sheet gives an insight in the fundamentals of analytical techniques applied in biodegradable materials' analyses and has the aim to be a supportive document for companies planning to include biodegradable polymers in new product development.

\subsection{Optical Microscope}

Microscopic observations of polymer surface changes are carried out by means of an optical microscope, equipped with a color digital camera at different magnification.

\subsection{Atomic Force Microscopy, AFM}

The surface structure of biodegradable polymers is also examined by means of atomic force microscopy. AFM 9fig. 5) observations are based on inter atomic forces and can be operated in standard fashion contact, allowing to obtain three-dimensional images. The maximum scanning area can be 130 microns $\times 130$ microns or 2 microns $\times 2$ microns, depending on the scanner used. Resolution in the plane $\mathrm{x}, \mathrm{y}$ can be up to a tenth of a nanometer. The AFM method does not require special preparation of samples for testing, and the analysis does not damage the polymer surface. 


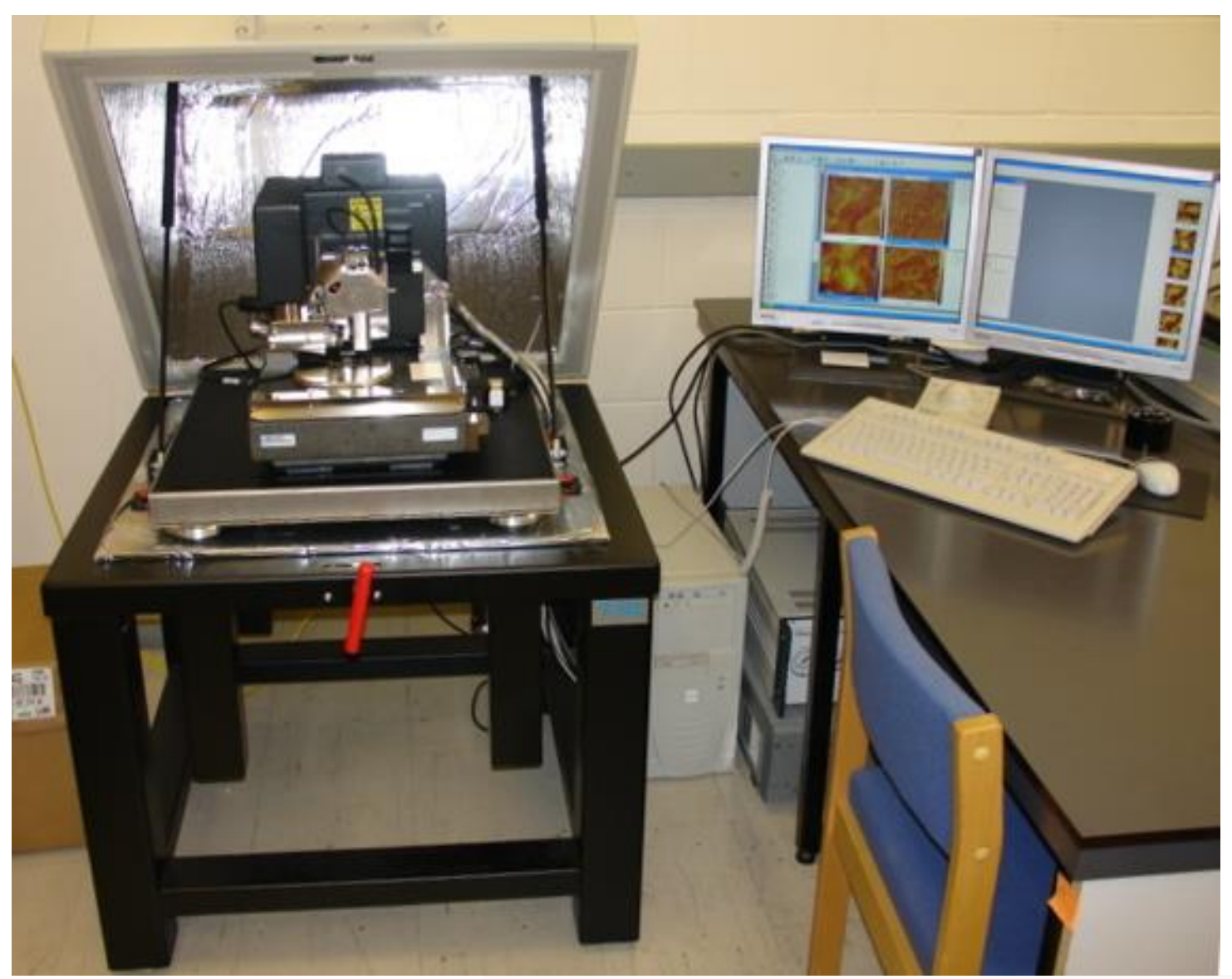

Figure 5: Atomic force microscopy (An atomic force microscope on the left with controlling computer on the right.)

\subsection{Dynamic Mechanical Analysis, Dma}

The dynamic mechanical analysis (fig.6) is used to examine the visco-elastic properties of the materials, such as stiffness, modulus and loss modulus, viscosity, damping properties, and the glass transition temperature. DMA determines the modulus of elasticity and the damping values by applying an oscillating force to the sample. This method can also be used to study the cross-linking kinetics and the phenomenon of gelation and vitrification. A wide range of measurement possibilities (under bending, tension, compression and shear condition) allows to receive a comprehensive characterization of the samples as a function of temperature, frequency, and stress or strain. 


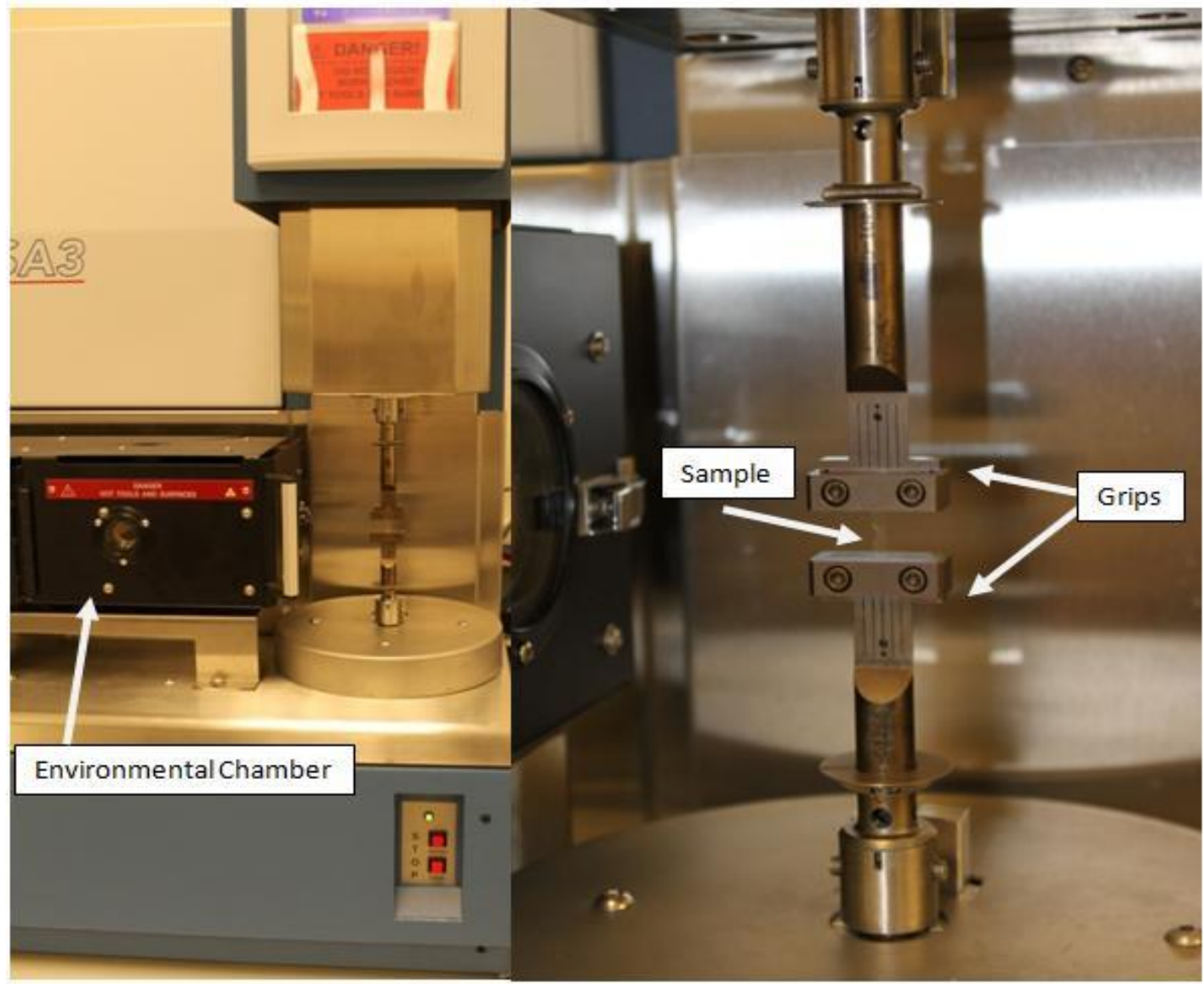

Figure 6: A typical DMA tester with grips to hold sample and environmental chamber to provide different temperature conditions. A sample is mounted on the grips and the environmental chamber can slide over to enclose the sample

\subsection{Gel Permeation Chromatography, GPC}

Gel permeation chromatography (fig. 7) is essential in polymer chemistry for measuring molar mass and their distribution. GPC is a kind of column liquid chromatography, and relies on separating the components of the mixture on silica gel or molecular sieves according to particle size. The GPC chromatograph is equipped with UV detectors and a differential refract to-meter, which allows to determine the polymers' dispersity and the average molar mass. Molar mass calculation is based on a calibration using narrow polystyrene or poly-methyl-methacrylate standards. The system can operate in a different solvent for example chloroform or tetra-hydro furan. 


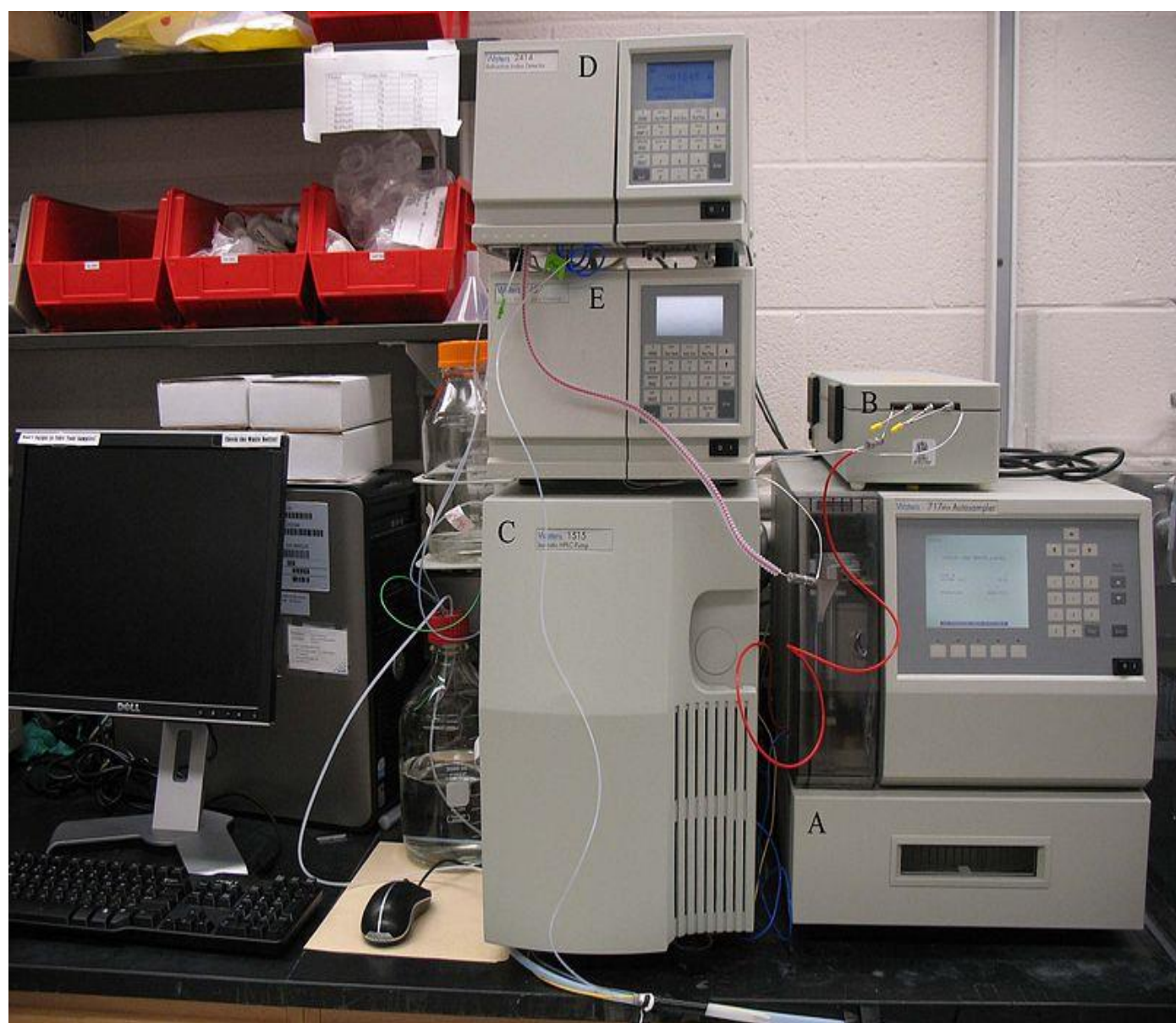

Figure 7: A typical GPC instrument including: A. Auto sampler, B. Column, C. Pump, D. RI detector, E. UV- vis detector

\subsection{Differential Scanning Calorimetry, DSC}

Differential scanning calorimetry (fig. 8) monitors heat effects associated with physical transitions and chemical reactions as a function of temperature. In a DSC the difference in heat flow to the sample and a reference at the same temperature, is recorded as a function of temperature. Since the DSC experiment is at constant pressure, heat flow is equivalent to enthalpy changes. Measurements are carried out using a differential calorimeter with high and constant calorimetric sensitivity. Differential calorimeter measures temperature of the first and second order transition, enthalpy changes, and allows to the study the kinetics of physical processes and chemical reactions, heat capacity measurement, and the measurement of substance purity. Measurement temperature range for typical polymers is $-180^{\circ} \mathrm{C}$ to $550^{\circ} \mathrm{C}$.

The DSC analysis is used to study phase transitions or chemical reactions. 


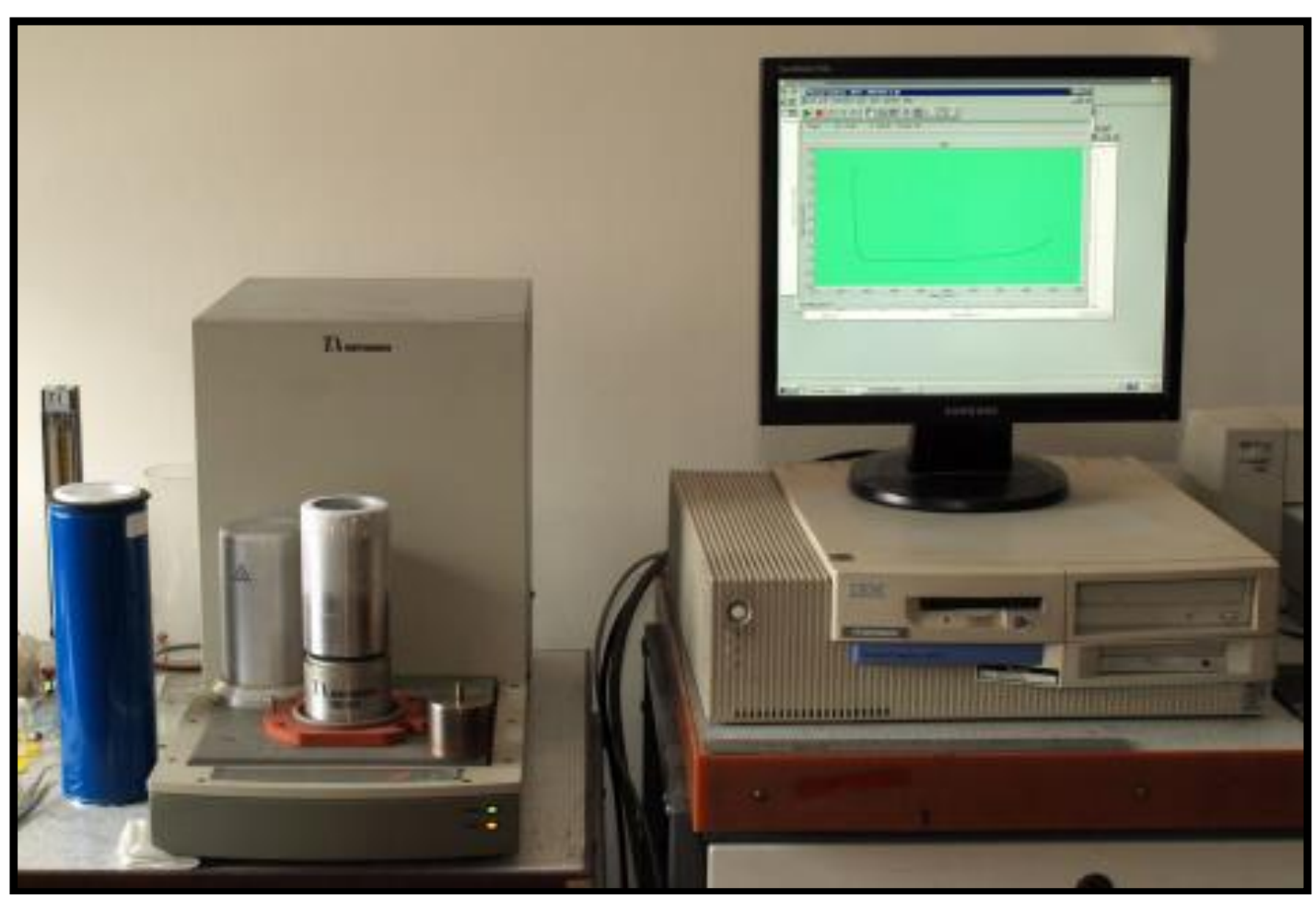

Figure 8: Differential scanning calorimetry

\subsection{Nuclear Magnetic Resonance spectroscopy, NMR}

Nuclear magnetic resonance spectroscopy is one of the most widely used spectroscopic techniques in chemistry and medicine. Spectroscopy is based on excitation of nuclear spins in a magnetic field by a quick change of the magnetic field, and then recording the electromagnetic radiation. NMR is therefore one of the emission spectroscopy methods assuring high accuracy and reproducibility. NMR spectra are obtained by using different types of nuclear magnetic resonance spectrometers, such as a Varian VXR 300 and Unity Inova 300 with high-resolution. They allow measurements over a wide frequency range (e.g.: $13 \mathrm{C}, 14 \mathrm{~N}, 15 \mathrm{~N}, 17 \mathrm{O}, 23 \mathrm{Na}, 31 \mathrm{P}, 39 \mathrm{~K}$ ) with simultaneous processing and storage of data. Appropriate equipment spectrometer allows to measure relaxation times, carbon bond order determination of selective methods (e.g. DEPT) and two-dimensional measurement of 2D-NMR. NMR spectroscopy is used in research of optical properties of polymers, for potential use in optoelectronics, the analysis of the polymer chains structure and assigning resonance lines, present in the NMR spectrum, corresponding structural elements of the chain of test samples.

NMR spectroscopy is also used in studies of biodegradable polymers in terms of environmental protection also in studies of new polymers, which while preserving utility properties allows to obtain a film's ability to biodegradation. The nuclear magnetic resonance spectroscopy of highresolution $1 \mathrm{H}$ and 13C NMR is used for analysis of the structure of biodegradable polymer chains. Objects of the study are lactide homo-polymer chains or amorphous poly-(3-hydroxybutyrate) chains, copolymers of lactide with glycolide, copolymers of lactide with caprolactone and copolymers glycolide with caprolactone. For the purpose of the analysis of the microstructure of biodegradable polymers' chains new methodologies are being developed. 
Nuclear magnetic resonance spectroscopy (NMR) (fig. 9) allows to get insight in the polymer chain structure as a result of which it will be possible to identify the proper structure for the application purposes.

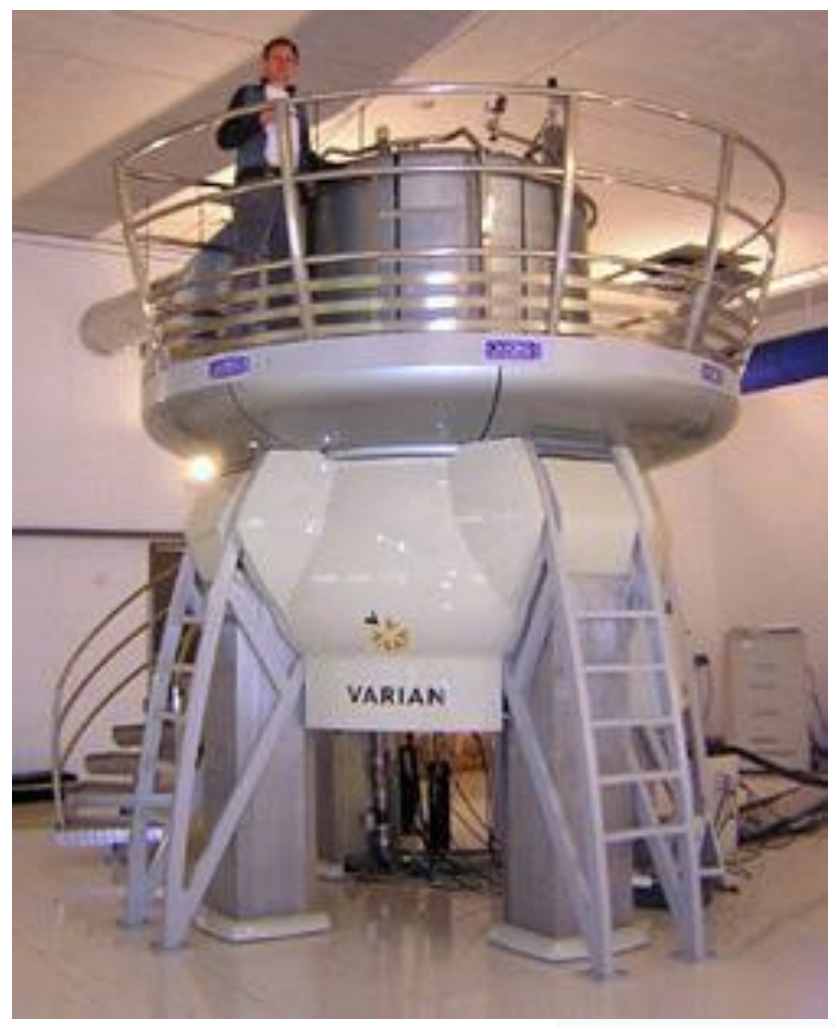

Figure 9: Nuclear magnetic resonance spectroscopy (A $900 \mathrm{MHz}$ NMR instrument with a 21.1 T magnet at HWB-NMR, Birmingham, UK)

\subsection{Absorption Spectroscopy}

Light spectroscopy is a group of spectroscopic techniques, which use electromagnetic radiation in the range from deep ultraviolet to far infrared. The most widely used technique is the infrared absorption spectroscopy (IR). Light in the IR range has a length similar to the length of the chemical bond. Passing through the sample of the test substance, radiation is selective absorbed by vibrations excitation of the chemical bonds of a length corresponding to the length of the wavelength absorbed.

In this way the spectrum is a series of sharp signals corresponding to vibrations set constraints. Another frequently used technique is absorption spectroscopy (fig.10) in the ultraviolet-visible spectral region, UV-VIS. This means it uses light in the visible and adjacent (near-UV and nearinfrared (NIR)) ranges. Radiation in this range is absorbed by vibration excitation of larger molecular fragments. Spectroscopy does not provide too much information about the structure of molecules, but it is helpful in analyzing their potential electro-optical properties. On the other hand, light reflectance spectroscopy is rarely applied. However, it is useful to determine the chemical composition and electro-optical properties of the surface of a variety of substances. IR spectra (4000-400 cm-1) was obtained using spectrometers such as BIO-RAD FTS-40A type equipped 
with dynamic arrangement system and a temperature table $\left(20^{\circ} \mathrm{C}\right.$ to $\left.250^{\circ} \mathrm{C}\right)$. The high quality of the spectra obtained by Fourier transformation and processing of computer data allows to further study the polymers' structure. Studies conducted using the infrared absorption spectroscopy technique through database spectra allows unambiguous identification of bonds present in the polymer sample.

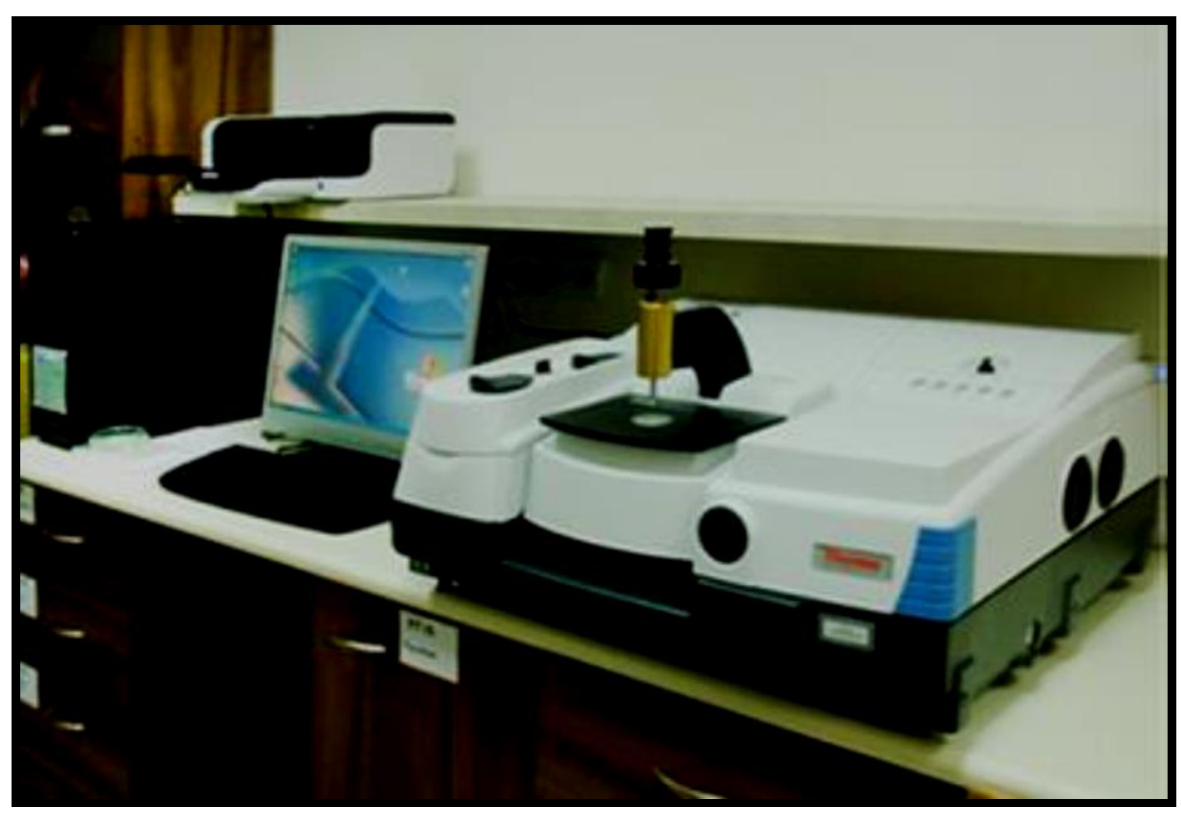

Figure 10: Absorption spectroscopy

\subsection{Mass Spectrometry, MS}

Among the analytical techniques at present used for the characterization of polymers very important is mass spectrometry. This technique provides useful information about the molecular structure of the macromolecules and is a perfect complement to conventional spectroscopic methods such as nuclear magnetic resonance (NMR) and infrared absorption spectroscopy (IR). The recently important instrumental progress in the techniques of mass spectrometry, in particular, the discovery of new methods of "soft" ionization, such as matrix-assisted laser desorption ionization (MALDI) and electro-spray ionization (ESI) enabled the simplification of a long and complicated process analytical study of the polymers structure.

LCQ mass spectrometer (Finnigan MAT) (fig. 11) fitted with break enable ionization of samples by electro spray ionization (ESI) and atmospheric pressure chemical ionization (APCI), is a worldwide connection LC/MS analysis allows to perform the combined techniques of liquid chromatography (LC) and mass spectrometry (MS). The use of the ion trap analyzer enables high sensitivity full-range mass spectra up to $2000 \mathrm{Da}$. It can register both positive and negative mass spectra of the test compounds and the implementation of a multi-technique analysis of fragmentation (MS/MS and MSn). 


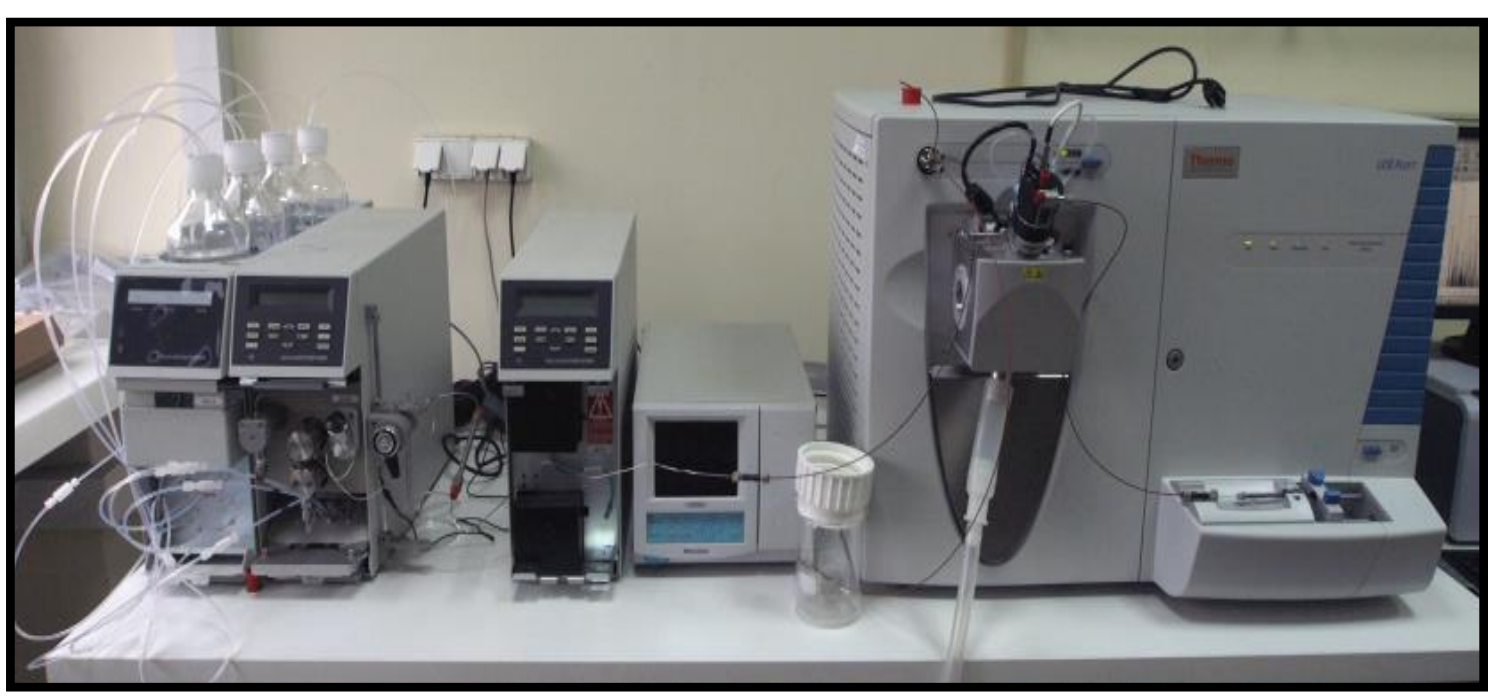

Figure 11: LCQ mass spectrometer

These techniques are used to determine the individual masses of macromolecules constituting the tested polymer and the separation due to degree of polymerization. Information obtained by mass spectrometry techniques is necessary to understand poly reaction mechanisms, in which may occur both linear macromolecules and cyclic oligomers (for example by an intra-molecular transesterification). The use of modern "soft" ionization methods such as MALDI and ESI in combination with multi mass spectrometry makes a huge contribution to research development in the field of chemistry, pharmacy and biology. In current years, more often "soft" ionization method is used in the structure study of the biodegradable synthetic polymer, comprising:

- Verification of chemical homogeneity of the polymer and to determine the chemical structure of end groups,

- Determination of the molar mass and dependent on the synthesis process the molar weight distribution,

- Determination of the chemical composition and distribution of the series of units to individual macromolecules of copolymers.

Multistage mass spectrometry techniques (MSn) are also used in studies of usual biopolymers, including the end-group analysis and to study the mechanism of the fragmentation of selected molecular ions (obtained by electrospray ESI) individual macromolecular biopolymers from the group of poly (3-hydroxybutyrate), PHB.

Investigation of biodegradable polymers carried out using ESI-MSn technique (fig.12) possible to decide the chemical structure of degradation products, and the course of their bio- assimilation and, consequently, allow to establish the relationship between the structure of macromolecules and their behavior during biodegradation. 


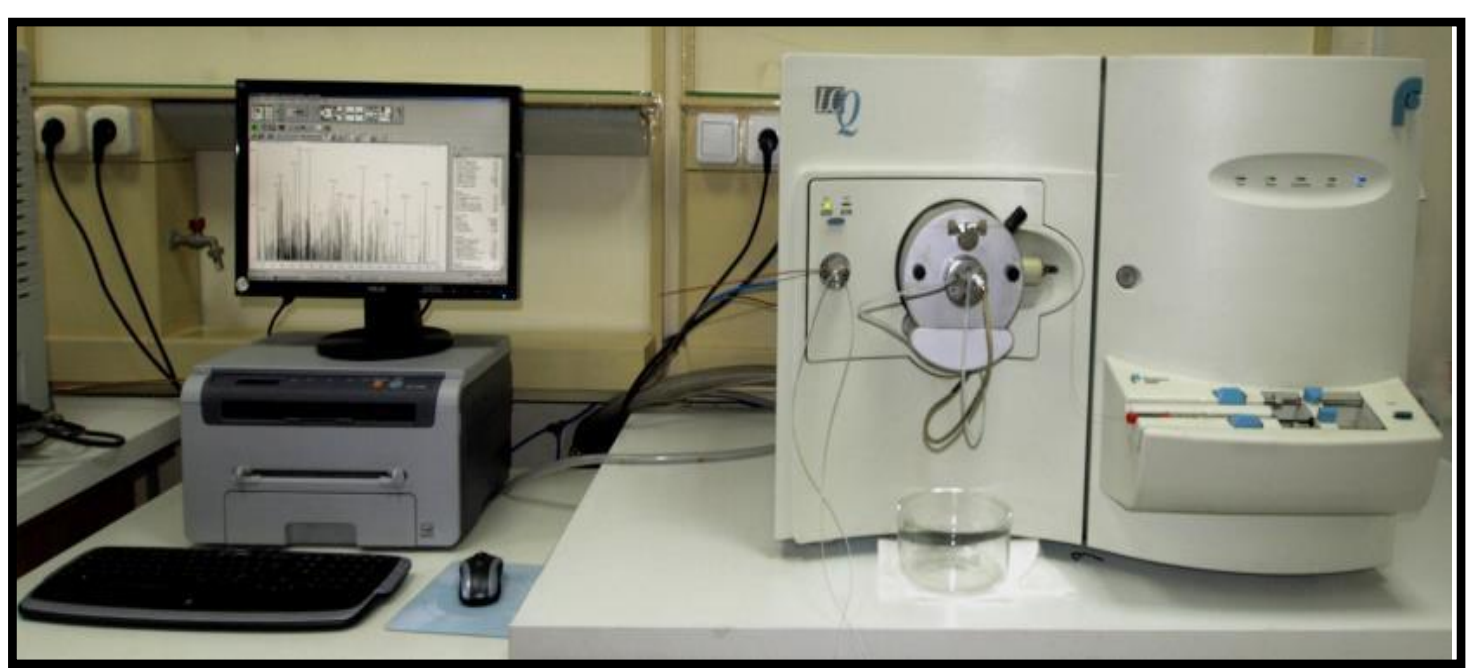

Figure 12: ESI-MSn technique

Detailed analysis of the mass spectrum and its transformation into a "mapping" - showing the presence of oligomeric fractions with different structures and allowing quantitative assessment of the observed progressive degradation due to changes in the distribution of these oligomersdelivers enough information to propose appropriate degradation mechanisms. Information on the microstructure of biodegradable polymer chains is a qualification for designing appropriate chemical structures required for biodegradable materials and helps in controlling their mechanical properties, process capability and time degradation.

\section{Conclusions}

Knowledge on biodegradable polymers' structures is essential for the selection of such materials for specific applications. In recent years, much attention has been given to organic recycling of biodegradable polymeric materials, enabling the controlled biological decomposition of these polymers to products, which are safe and friendly to the environment and human life and health. Products made from biodegradable polymers after their disposal are subjected to organic recycling processes. This significantly reduces the environmental charge with waste, and allows for their rational utilization by industrial composting.

In order to get their products certified as being biodegradable, producers have to perform biodegradation test of their products and/or materials in an accredited laboratory. These tests can be done at any stage of the product development process. The progress in (bio) degradation is determined by differential parameters such as macroscopic and microscopic changes in the polymer surface, changes in molar mass and weight loss and changes in microstructure. Appropriate measurements are performed using differential analytical techniques. The differential scanning calorimetry (DSC), the atomic force microscopy (AFM), the dynamic method of thermal analysis (DMA), gel permeation chromatography (GPC), and mass spectrometry (MS) as well as spectroscopy methods: nuclear magnetic resonance (NMR) and infrared absorption (IR), are used for observations of materials changes in the degradation process and complement each other. The NMR and IR spectroscopy allows to analyze polymeric materials' structures, and to track changes in the polymer chains microstructure due to the degradation process. Moreover the MS technique is used in the analysis of the oligomeric fraction formed during the degradation of the polymers. 
Summarize the results in words rather than numbers and elaborate on the extent to which the objectives of the study were met. Do not include information from a literature search. Instead, focus on the primary conclusions of the study. Interpret the results for the audience; do not leave any results unexplained. Scientific writing cannot be left open for interpretation.

Be sure to avoid over-interpreting the results and make general conclusions that cannot be justifiably derived from the parameters of the study. Discuss any implications and limitations of the study as well as to what extent the conclusions are in concert with other researchers. The main results should be presented clearly and briefly, insisting on their significance and degree of novelty.

This section may also include also include discussion on theoretical and methodological implications of findings.

\section{References}

[1] Nathalie Lucas, Christophe Bienaime, Christian Belloy, Michèle Queneudec, Françoise Silvestre, José-Edmundo Nava-Saucedo, // Chemosphere 73 (2008), pp 429-442, Indian Journal of Biotechnology, Vol. 4, April 2005, pp 186-193; \& Polymer degradation www.Wikipedia.com

[2] Leslie White, august 20, 2017, www.merlinproject.org.uk, // (Dommergues and Mangenot, 1972)// (Grima, 2002; Belal, 2003). Figure 1: https://doi.org/10.1186/s40643-017-0145-9

[3] Hydrolysis, 2015 polymerdatabase.com Figure 2: Leslie White, august 20, 2017, www.merlinproject.org.uk

[4] Jan F. Rabek, chapter 4, pp 425, c6cp05064f-s1_hi-res.gif Figure 3: Hydrolysis, 2015 polymerdatabase.com

[5] Decarboxilation degradation- www.Wikipedia.com

[6] C. Booth**(Torrance research laboratory, Synthetic rubber division of shell chemical company, Torrance, California), pp 471 (1963).

[7] Polish J. of Environ. Stud. Vol. 19, No. 2 (2010), 225-266// Katarzyna Leja*, Grażyna Lewandowicz, Department of Biotechnology and Food Microbiology Poznań University of Life Sciences, Wojska Polskiego 48, 60-627 Poznań, Poland. Chamy, Rolando (June 14, 2013). Biodegradation - Life of Science. InTech. ISBN 978-953-51-1154-2.

[8] Biodegradable polymers, Wikipedia Bastioli, editor, Catia (2005). Handbook of biodegradable polymers.

Shawbury, Shrewsbury, Shropshire, U.K.: Rapra Technology. ISBN 9781847350442.

Kumar, A.Ashwin; K., Karthick (2011). "Properties of Biodegradable Polymers and Degradation for Sustainable Development". International Journal of Chemical Engineering and Application:s 164-167. doi:10.7763/IJCEA. 2011.V2.95 (https://doi.org/10.7763\%2FIJCEA.2011.V2.95.)

Figure 4: https://doi.org/10.1186/s40643-017-0145-9

[9] Aamer Ali Shah *, Fariha Hasan, Abdul Hameed, Safia Ahmed

Department of Microbiology, Quaid-i-Azam University, Islamabad, Pakistan/ Biotechnology Advances 26 (2008) 246-265,

Table:1 (http://www.envis-icpe.com, Plastics recycling-Economic and Ecological Options. ICPE 2006;4(4):1-12).

http://en.wikipedia.org/w/index.php?title=Polyhydroxybutyrate\&oldid=189442759.

Accessed February 14, 2008.

http://www.chemquest.com/store/polyvinyl-acetate-european-adhesives. html, 2006. 
[10] Aamer Ali Shah *, Fariha Hasan, Abdul Hameed, Safia Ahmed// Biotechnology Advances 26 (2008) 246-265// www.elsevier.com/locate/biotechadv

(Biodegradation of plastics: Gu et al., 2000a// Glass and Swift, 1989// Artham and Doble, 2008; Gu et al., 2000b// Swift, 1997// Kamal and Huang, 1992// Griffin, 1980// Goldberg, 1995// Goldberg, 1995// Winursito and Matsumura, 1996// Heidary and Gordon, 1994// Hiltunen et al., 1997; Nakayama et al., 1996// Lehmann et al., 1995; Xu et al., 1998// Doi, 1990; Gu et al., 2000b// Frazer, 1994; Hamilton et al., 1995// and Bartha, 1997; Narayan, 1993// Barlaz et al., 1989).

(Biodegradation of polyhydroxyalkanoates: Williams and Peoples, 1996// Gilmore et al., 1990// Doi et al., 1992// Luzier, 1992// Scott, 1999// Lee, 1996// Takaku et al., 2006// Shah et al., 2007; Shah, 2007// Sang et al., 2000// Whitchurch and Terence, 2006// Kim et al., 2001).

(Biodegradation of synthetic plastics: Albertson, 1980; Cruz- Pinto et al., 1994; Albertson et al., 1994// Albertson and Karlson, 1990; Albertson et al., 1987; Huang et al., 1990// Huang et al., 1992). (Polyethylene: Yamada- Onodera et al., 2001// Kwpp and Jewell, 1992/ Albertson et al., 1994// Bikiaris et al., 1999// al., 1991; Glass and Swift, 1989; Imam et al., 1992; Gu, 2003// Bonhomme et al., 2003; Wang et al., 2004// Bonhomme et al., 2003; EI-Shafei et al., 1998; Yamada-Onodera et al., 2001// Shah, 2007//(http://www.dasma. dlsu.edu.ph/offices/ufro/sinag/Jacinto.htm)// Hasan et al., 2007).

(Polyvinyl chloride: Braun and Bazdadea, 1986; Owen, 1984).

(Polystyrene: Tsuchii et al., 1977).

(Polymer blend: Weiland et al., 1995// Albertsson and Karlsson, 1993// Griffin, 1977/ Johnson et al., 1993; Bikiaris et al., 1998). // Lee et al., 1991// Cornell et al., 1984// Evangelista et al., 1991// Shogren et al., 1992).// Tokiwa et al., 1994; Bastioli, 1994// Nishioka et al., 1994// Doi et al., 1992// Jayasekara et al., 2005// Ratto et al., 1999// Pagga et al., 2001// Tudorachi et al., 2000// Park et al., 1994; Bastioli, 1994; Haschke et al., 1998// Ikejima et al., 1999// Torres et al., 1996// Pranamuda et al., 1997; Pranamuda and Tokiwa, 1999//Tomita et al., 1999//Fukuzaki et al., 1989).

Table 2: A.A. Shah et al. / Biotechnology Advances 26 (2008) 246-265,

[11] Nathalie Lucas, Christophe Bienaime, Christian Belloy, Michèle Queneudec, Françoise Silvestre, José-Edmundo Nava-Saucedo, // Chemosphere 73 (2008) 429-442.

[12] Wanda Sikorska and Henryk Janeczek, Innovation value chain development for sustainable plastics in central Europe//www.plastice.org

Figure 5: www.Wikipedia.com

Figure 6: www.Wikipedia.com

Figure 7: www.Wikipedia.com

Figure 8: Nathalie Lucas, Christophe Bienaime, Christian Belloy, Michèle Queneudec, Françoise Silvestre, José-Edmundo Nava-Saucedo chemosphere 73 (2008) 429-442

www.elsevier.com/locate/chemosphere

Figure 9: www.Wikipedia.com (A $900 \mathrm{MHz}$ NMR instrument with a $21.1 \mathrm{~T}$ magnet at HWBNMR, Birmingham, UK)

Figure 10, 11, 12: Nathalie Lucas, Christophe Bienaime, Christian Belloy, Michèle Queneudec, Françoise Silvestre , José-Edmundo Nava-Saucedo chemosphere 73 (2008) 429-442 www.elsevier.com/locate/chemosphere

*Corresponding author.

E-mail address: adarsh1307@ gmil.com/hardesh11@yahoo.co.in 